\title{
Modelling the effects of gravity waves on stratocumulus clouds observed during VOCALS-UK
}

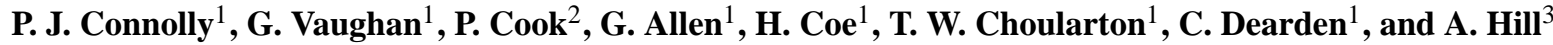 \\ ${ }^{1}$ School of Earth, Atmospheric and Environmental Sciences, The University of Manchester, Manchester, UK \\ ${ }^{2}$ Department of Meteorology, University of Reading, Reading, UK \\ ${ }^{3}$ Met Office, Exeter, UK
}

Correspondence to: P. J. Connolly (p.connolly@man.ac.uk)

Received: 18 December 2012 - Published in Atmos. Chem. Phys. Discuss.: 15 January 2013

Revised: 8 June 2013 - Accepted: 24 June 2013 - Published: 29 July 2013

\begin{abstract}
During the VOCALS campaign spaceborne satellite observations showed that travelling gravity wave packets, generated by geostrophic adjustment, resulted in perturbations to marine boundary layer (MBL) clouds over the southeast Pacific Ocean (SEP). Often, these perturbations were reversible in that passage of the wave resulted in the clouds becoming brighter (in the wave crest), then darker (in the wave trough) and subsequently recovering their properties after the passage of the wave. However, occasionally the wave packets triggered irreversible changes to the clouds, which transformed from closed mesoscale cellular convection to open form. In this paper we use large eddy simulation (LES) to examine the physical mechanisms that cause this transition. Specifically, we examine whether the clearing of the cloud is due to (i) the wave causing additional cloud-top entrainment of warm, dry air or (ii) whether the additional condensation of liquid water onto the existing drops and the subsequent formation of drizzle are the important mechanisms. We find that, although the wave does cause additional drizzle formation, this is not the reason for the persistent clearing of the cloud; rather it is the additional entrainment of warm, dry air into the cloud followed by a reduction in longwave cooling, although this only has a significant effect when the cloud is starting to decouple from the boundary layer. The result in this case is a change from a stratocumulus to a more patchy cloud regime. For the simulations presented here, cloud condensation nuclei (CCN) scavenging did not play an important role in the clearing of the cloud. The results have implications for understanding transitions between the different cellular regimes in marine boundary layer (MBL) clouds.
\end{abstract}

\section{Introduction}

It is well recognised that marine boundary layer (MBL) stratocumulus ( $\mathrm{Sc}$ ) clouds are important to climate, due to their large areal coverage and radiative properties (e.g. Bretherton et al., 2004). It is also known that MBL Sc are influenced indirectly by aerosols acting as cloud condensation nuclei (CCN) (Twomey, 1977; Albrecht, 1989). Perhaps less discussed in the literature are the connections between synopticscale circulations and the properties of MBL Sc.

Recently however, Allen et al. (2012) have presented observations from the tenth Geostationary Operational Environmental Satellite (GOES10) during the VAMOS OceanCloud-Atmosphere-Land Study (VOCALS) field campaign that showed the effects that propagating gravity waves have on the formation of open cellular structures within MBL Sc. In their study, gravity waves propagating horizontally perpendicular to the mean wind were found to modulate the height of the cloud-topped boundary layer over the south-east Pacific Ocean (SEP) by up to $400 \mathrm{~m}$ peak-to-trough. They were found to induce both reversible and irreversible changes in the cloud-radiative and dynamical properties, such that a region of clear sky was evident in the trough of the passing wave fronts, which in some cases persisted and developed into so-called pockets of open cells. Allen et al. (2012) showed that the epicentre of the waves coincided with a large negative residual in non-linear balance close to the position of the subtropical jet stream. This therefore suggested that the source of energy for the waves was geostrophic adjustment in the sharply divergent flow associated with a disturbed jet stream. 
The mechanism for the clearing of the cloud was briefly discussed by Allen et al. (2012) although not addressed fully and left for further work. The presence of increased rain in the crest of the waves, observed using the advanced microwave sounding radiometer-EOS (AMSR-E) and the Moderate Resolution Imaging Spectroradiometer (MODIS) provided evidence that the mechanism might be due to the cloud layer being "rained out" because of increased condensation of water vapour onto the cloud drops, followed by their collision and coalescence to form rain drops, which then fell out of the cloud. They noted that this is a likely mechanism because the cloud appeared to transition to clear sky in limited regions only, which were thought to be regions of higher liquid water path (LWP) or lower drop number concentration.

The relatively clear-sky regions observed by Allen et al. (2012) are reminiscent of pockets of open cells POCs observed during the second dynamics and chemistry of marine stratocumulus (DYCOMS-II) campaign (see overview by Stevens et al., 2005). Open and closed cells are two of the most frequent types of cloud self-organisation, observed within Sc, referred to as mesoscale cellular convection MCC (Hubert, 1966). The "open" and "closed" descriptors apply if the central part of the cell is clear or cloudy respectively; however, less frequent forms of self-organisation are also formed within Sc, such as actinoform clouds (see overview by Garay et al., 2004). Furthermore, both open and closed forms of MCC bear a striking resemblance to RayleighBénard convection (Agee, 1984), which is well studied. Although the mechanisms responsible for the transition from closed to open cell forms are unclear, it is evident that the two cellular regimes form when the boundary layer is deeper than $\sim 1 \mathrm{~km}$ and that closed cells form over cold ocean currents, while open cells form preferentially over warm ocean currents (see Wood and Hartmann, 2006, and references therein).

Wood et al. (2011a) presented an aircraft study of the transition from closed to open cellular convection observed during the VOCALS campaign. They found that the POCs consisted of intermittent precipitating cumulus $(\mathrm{Cu})$ clouds that detrained into very optically thin stratiform cloud. A key finding was that the precipitation rates within the POCs were not significantly different to those within the closed cell regime, leading to the argument that precipitation is not a sufficient condition for the formation of POCs. This is a significant finding and one that is highly relevant to this study. However, it was clear from the work of Wood et al. (2011a) that the cells within the POCs were often surrounded by a "boundary cell" with divergent cold pools at lower levels, convergence in the middle of the boundary layer and divergence at the top, thus suggesting that precipitation processes may play a role in maintaining the POCs once they form. This was also confirmed by large eddy simulation LES modelling of the same case (Berner et al., 2011) and is consistent with earlier LES studies of the formation of POCs (Wang et al., 2010), which argued that precipitation formation is necessary for the maintenance of long-lived POCs. Further evidence of the importance of precipitation processes was that the deeper clouds within the POCs detrained air that was very low in $\mathrm{CCN}$ concentrations, and thus $\mathrm{CCN}$ scavenging by drizzle was thought to be very efficient.

The idea that mid-latitude cold fronts may emit distinct gravity wave packets has been around since the 1970s and indeed they have been observed by aircraft recently to the west of the British Isles ahead of a rearward-sloping cold front (Knippertz et al., 2010). Numerical models often have difficulty capturing the precise details of these waves, and can often generate spurious gravity waves due to the numerical methods employed. Indeed the Met. Office Unified Model (UM) used in the Knippertz et al. (2010) study was unable to accurately capture the wavelength of a pre-frontal gravity wave when run at $4 \mathrm{~km}$ resolution.

In this study we take the findings of Allen et al. (2012) further by performing semi-idealised LES modelling of MBL Sc upon which we impose the effects of gravity waves. Due to the relatively small domain sizes employed and the difficulties in capturing the dynamics of gravity waves within numerical models, we do not focus on the details of wave generation. Rather, we look at the sensitivity of the Sc to lifting and lowering of the layer by a "kinematic gravity wave", the details of which are specified from observed GOES10 imagery, to examine the physics behind the clearing of the Sc. We point out that the gravity wave packets under consideration in this paper have a different source to the "upsidence" wave described by Garreaud and Muñoz (2004) and Rahn and Garreaud (2010), which is due to mechanical blocking by the Andes of the westerly flow above the boundary layer. Such effects have been investigated using LES by Jiang and Wang (2012) by applying upsidence-subsidence waves of time periods from 6 to $48 \mathrm{~h}$, and it was found that, perhaps because of the relatively long wave period, precipitation is significant in the clearing of the cloud. In contrast to the study by Jiang and Wang (2012), we investigate the role of waves with a time period of $\sim 1 \mathrm{~h}$, associated with the jet stream, and investigate how the cloud responds during different times of the day. We therefore address (i) whether such short period waves are sufficient for drizzle to be significant to the breakup of the cloud, and (ii) whether the diurnal cycle of short wave radiation plays a role in the break-up of the cloud.

There are two hypotheses to be tested. These are that the clearing and consequent breaking up of the cloud is a result of the following:

1. Increased entrainment of dry air into the cloud layer, which reduces the total water content to levels below the saturation vapour mixing ratio at the initial altitude of the cloud level. This results in evaporation of the cloud when it descends to the original level.

2. Additional condensation followed by collision and coalescence, which leads to drizzle falling out of the cloud. This drizzle then evaporates below the cloud, cooling 


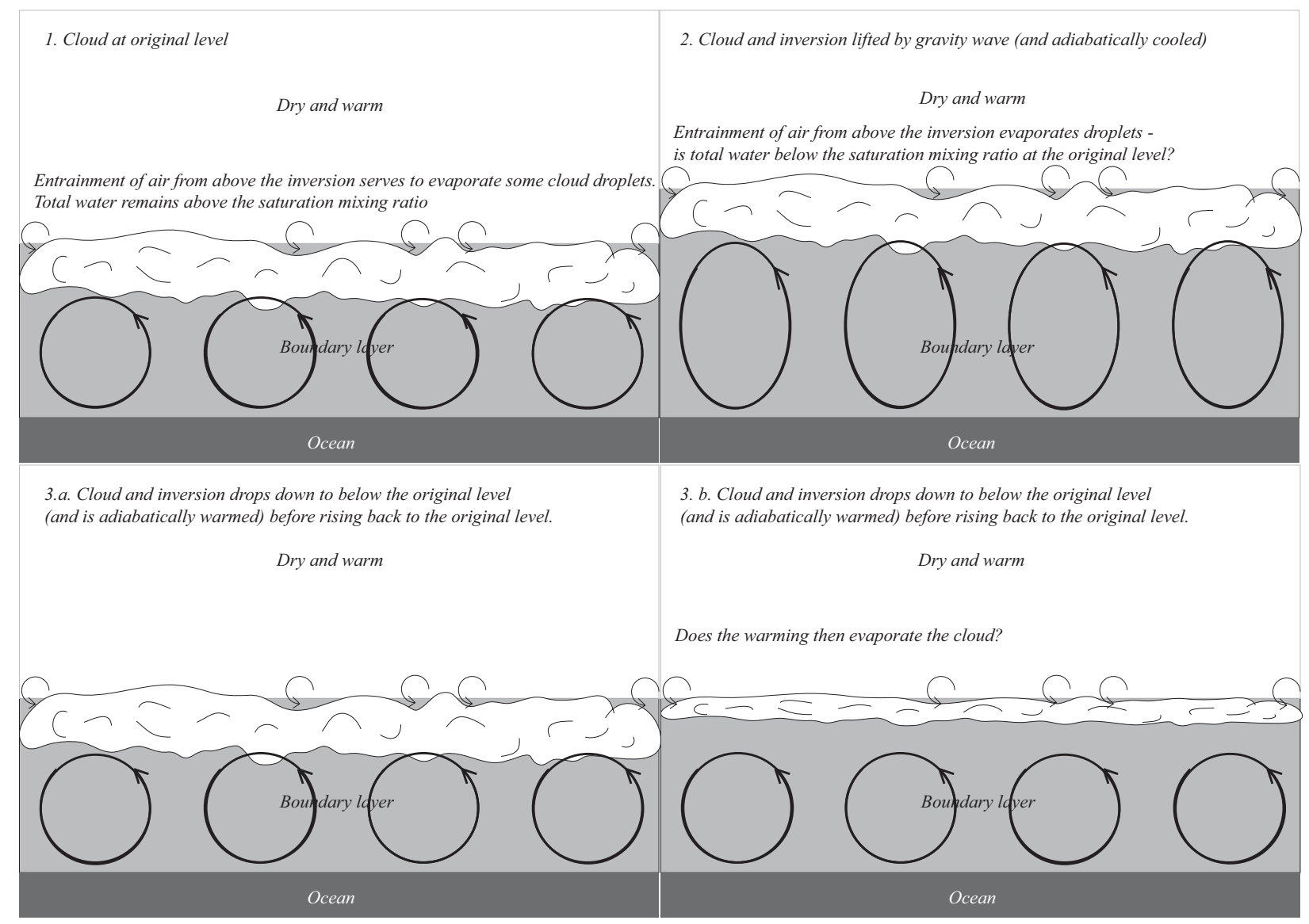

Fig. 1. Schematic of the first hypothesis to be tested: does the cloud clear due to additional cloud-top entrainment as a result of the wave? (1) Cloud is at its equilibrium level; (2) cloud and the inversion are lifted by the gravity wave, which results in higher liquid water contents due to cooling, entrainment causes increased evaporation relative to (1); (3) if the total water mixing ratio is still above the saturation vapour mixing ratio at the cloud's equilibrium level, then the cloud will be maintained; (4) if the total water mixing ratio is below saturation, then the cloud will evaporate and clear and the air close to the inversion may decouple from fluxes of water below.

the air below and cutting off the boundary layer thermal and moisture circulation.

These processes are not necessarily independent and may both be in play; they are illustrated and explained in Figs. 1 and 2. It is hypothesised that enhanced entrainment occurs (as shown in Fig. 1) because of enhanced evaporation at the cloud top during entrainment events. The larger liquid water contents that are present in the crest of the wave result in more evaporative and radiative cooling, which enhances turbulence and mixing at cloud top. Both mechanisms appear to be plausible (indeed the second has been highlighted by previous studies), but it is important to understand which is the dominant mechanism so that if parameterisations are to be developed, they may take account of the relevant physics and thus be more realistic.

\section{Background to the VOCALS study}

The VOCALS project took place from 15 October to 15 November 2008 in the SEP to investigate the interactions between land, sea and atmosphere with the aim of improving representation of processes in the region in both global and regional models. Detailed descriptions of the international effort have been presented and discussed in the scientific literature (e.g. Wood et al., 2011b,a; Allen et al., 2011) and so the details will not be repeated here; rather we will present an overview of the campaign and discuss the measurements relevant to this paper.

The observations of gravity wave packets affecting MBL Sc were taken from GOES10 on several days, although the clearest evidence was on 8 October 2008. Unfortunately there were no in situ observations on this day and so the model simulations presented in this paper are idealised and have been developed from observed statistics taken from VOCALS flight data (Bretherton et al., 2010; Allen et al., 2011). 


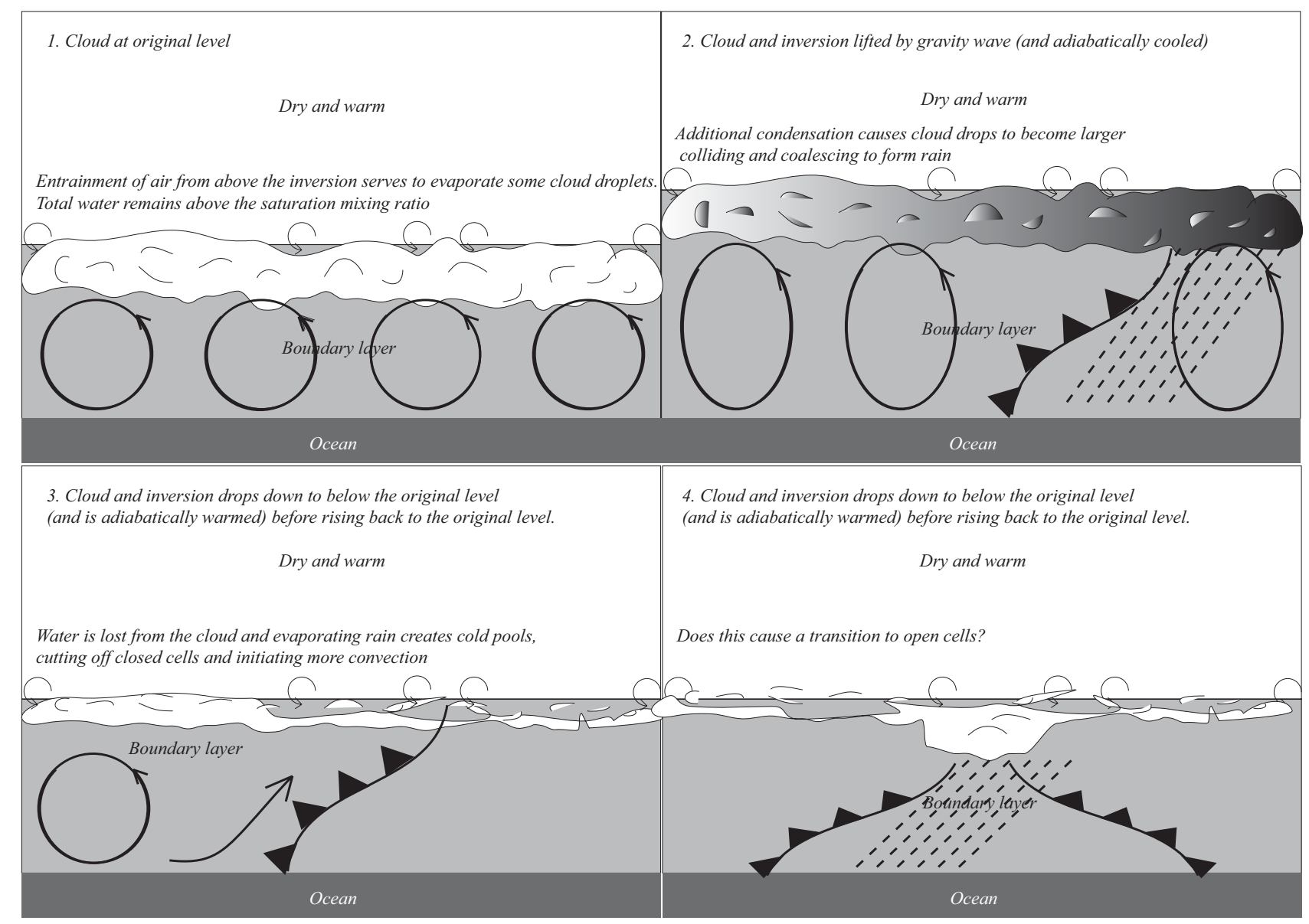

Fig. 2. Schematic of the second hypothesis to be tested: does the cloud clear due to drizzle forming and falling out? (1) Cloud is at its equilibrium level; (2) cloud and the inversion are lifted by the gravity wave, which results in higher liquid water contents and drizzle formation, forming cold pools; (3) the boundary layer eddies are cut off by the cold pools and the cloud clears; (4) boundary cells form.

Allen et al. (2011) partitioned the VOCALS measurements into three regions, based on the location from the shore. These were coastal (to the east of $75^{\circ} \mathrm{W}$ ), transitional (between $75^{\circ} \mathrm{W}$ and $80^{\circ} \mathrm{W}$ ) and remote (to the west of $80^{\circ} \mathrm{W}$ ). They presented quad-log-normal fits to the median of the number-size distributions of aerosol particles measured in the MBL for each of these regions (these are shown in Table 1). The data show a clear trend of decreasing accumulation mode aerosol concentrations moving from the coastal to the remote region. Other statistics quantifying the region have been presented by Bretherton et al. (2010). Boundary layer height was $\sim 1000 \mathrm{~m}$ close to the coast, increasing to $\sim 1500 \mathrm{~m}$ at $85^{\circ} \mathrm{W}$, whereas sea surface temperature (SST) increased to a maximum close to the coast (see Bretherton et al., 2010). These factors likely play a role in determining the location of POCs over the region, which tend to occur most frequently in the transition region and perhaps the remote region.

Figure 3 shows a case study that Allen et al. (2012) presented of a gravity wave triggering the formation of POCs within an area of otherwise overcast Sc. Throughout the day several gravity wave packets propagated in a north-east direction and eventually resulted in the cloud opening up (Fig. 3, centre) at 79 to $81^{\circ} \mathrm{W}$. This persisted and became more prevalent throughout the day (Fig. 3, right). The study will now focus on determining the mechanism that causes the cloud to clear.

\section{Methodology}

\subsection{Large eddy modelling (LEM)}

Version 2.4 of the UK Met. Office (Met. Office) large eddy model (LEM) (Gray et al., 2001) was used to simulate the interaction between dynamics, microphysics and radiation for an idealised case based on observations from the VOCALS campaign.

The LEM is an anelastic, nonhydrostatic numerical model, with prognostic equations for momentum and scalar fields such as potential temperature and moisture variables. Mass 

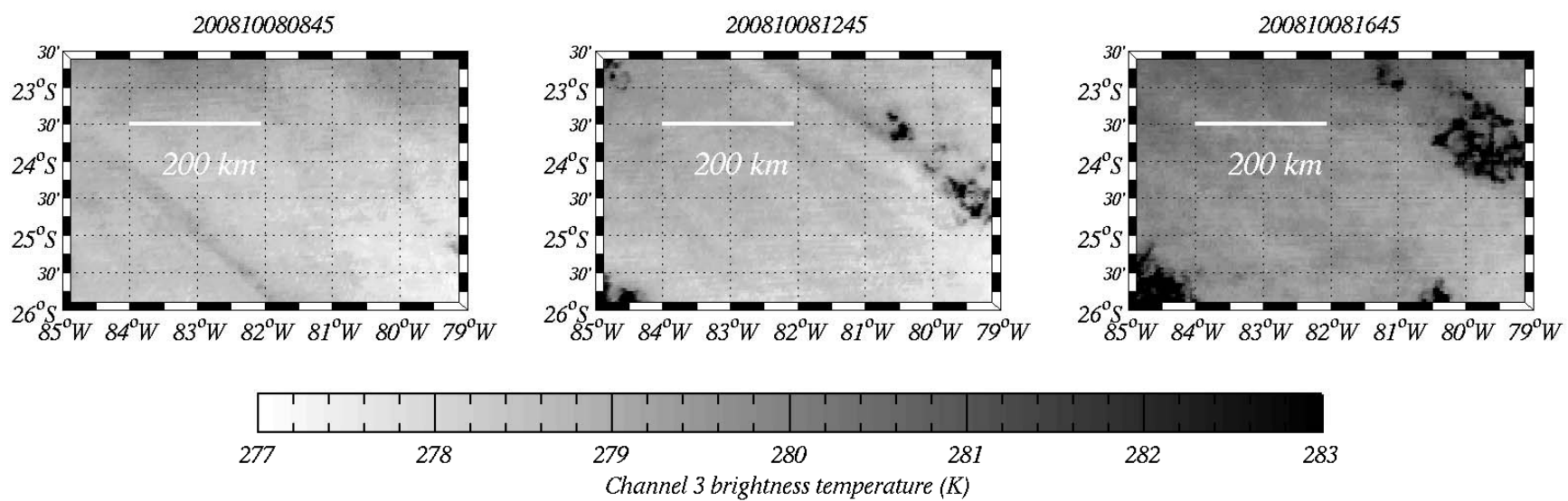

Fig. 3. GOES10 channel 3 brightness temperature imagery of gravity waves initiating POCs (Allen et al., 2012, adapted from). Left: brightness temperature observed at 08:45; centre: brightness temperature observed at 12:45; right: brightness temperature observed at 16:48. All times in the figure are GMT.

Table 1. Fit parameters to the measured aerosol size distributions observed during the VOCALS campaign. Reproduced following Allen et al. (2011).

\begin{tabular}{lllll}
\hline \multirow{2}{*}{ Mode } & Fit parameter & \multicolumn{3}{c}{ Within the MBL } \\
\cline { 3 - 5 } & & Coastal & Transitional & Remote \\
\hline 1 & $N_{\mathrm{L}}\left(\mathrm{cm}^{-3}\right)$ & $20.065 \pm 0.009$ & $13.278 \pm 0.803$ & $46.642 \pm 1.730$ \\
& $\log \left(\sigma_{g}\right)$ & $0.435 \pm 0.000$ & $0.260 \pm 0.019$ & $0.348 \pm 0.015$ \\
& $D_{\mathrm{m}}(\mu \mathrm{m})$ & $0.014 \pm 4.740$ & $0.013 \pm 0.000$ & $0.018 \pm 0.000$ \\
\hline 2 & $N_{\mathrm{L}}\left(\mathrm{cm}^{-3}\right)$ & $114.996 \pm 0.007$ & $155.208 \pm 1.085$ & $153.421 \pm 1.737$ \\
& $\log \left(\sigma_{g}\right)$ & $0.353 \pm 2.790$ & $0.497 \pm 0.004$ & $0.354 \pm 0.004$ \\
& $D_{\mathrm{m}}(\mu \mathrm{m})$ & $0.050 \pm 1.710$ & $0.042 \pm 0.000$ & $0.039 \pm 0.000$ \\
\hline 3 & $N_{\mathrm{L}}\left(\mathrm{cm}{ }^{-3}\right)$ & $268.099 \pm 0.008$ & $175.766 \pm 1.017$ & $166.774 \pm 1.992$ \\
& $\log \left(\sigma_{g}\right)$ & $0.444 \pm 1.704$ & $0.429 \pm 0.002$ & $0.465 \pm 0.006$ \\
& $D_{\mathrm{m}}(\mu \mathrm{m})$ & $0.157 \pm 3.272$ & $0.158 \pm 0.000$ & $0.154 \pm 0.001$ \\
\hline 4 & $\left.N_{\mathrm{L}}(\mathrm{cm})^{-3}\right)$ & $15.347 \pm 0.012$ & $0.813 \pm 1.724$ & $\mathrm{n} / \mathrm{a}$ \\
& $\log \left(\sigma_{g}\right)$ & $0.310 \pm 0.000$ & $0.350 \pm 0.860$ & $\mathrm{n} / \mathrm{a}$ \\
& $D_{\mathrm{m}}(\mu \mathrm{m})$ & $0.619 \pm 0.000$ & $1.839 \pm 1.808$ & $\mathrm{n} / \mathrm{a}$ \\
\hline & & & & \\
\end{tabular}

continuity is diagnosed via an elliptical equation and serves as a source term for momentum. The LEM explicitly resolves large-scale turbulent motions, which are responsible for most of the turbulent energy and transport, while parameterising sub-grid motions with a first-order turbulence scheme.

The majority of simulations presented use a vertical domain extending from the surface to $3 \mathrm{~km}$, while the horizontal domain is $16 \mathrm{~km} \times 16 \mathrm{~km}$ in extent. The horizontal resolution $(\Delta x, \Delta y)$ is $120 \mathrm{~m}$ and the vertical resolution $(\Delta z) 20 \mathrm{~m}$ below the inversion. Starting $100 \mathrm{~m}$ above the inversion to an altitude of $2000 \mathrm{~m}$ the vertical grid spacing was stretched to $50 \mathrm{~m}$. This results in a grid size of $128 \times 128 \times 105$ points on which the solutions were computed. In Sect. 4.8 we assess whether our findings are sensitive to both domain size and grid resolution.
The initialisation time was 08:00 GMT, which is approximately 03:00 LT. The simulation time for all cases is $12 \mathrm{~h}$ with a variable time step to satisfy two separate CourantFredrichs-Lewy (CFL) criteria. The first criterion was that the Courant number, $\sim u \times \frac{\Delta t}{\Delta x} \leq 0.2$, and the second was that the viscous stability parameter, $\sim \frac{4 \Delta t v}{\Delta x^{2}} \leq 0.2$, where $v$ is the viscosity of the flow, the dependence of which has a parameterised relation to the resolved part of the flow. The maximum time step is limited to $5 \mathrm{~s}$.

In all simulations the roughness length is set to $2.0 \times$ $10^{-3} \mathrm{~m}$ for momentum and $2.0 \times 10^{-4} \mathrm{~m}$ for scalars, consistent with values for an open sea surface. A sponge layer is applied to the top $500 \mathrm{~m}$ of the domain so that fields are relaxed back to initial conditions in this region. All simulations employ cyclic lateral boundary conditions. 
To initialise the model the vertical profiles of horizontal wind and geostrophic wind were set to a constant $u=$ $7.0 \mathrm{~m} \mathrm{~s}^{-1}$ and $v=-1.0 \mathrm{~m} \mathrm{~s}^{-1}$. Geostrophic wind forcing is required to maintain the horizontal winds, otherwise the effects of surface friction would reduce the wind speed throughout the simulation. The initial cloud liquid water content was set to be adiabatic leading up to the inversion and specified to be horizontally homogeneous throughout the model, while the initial drop number concentration was set to be $100 \mathrm{mg}^{-1}$ of air. The total number of $\mathrm{CCN}$ was set to be $500 \mathrm{mg}^{-1}$ of air below the inversion and to zero above the inversion, which is consistent with the VOCALS region (Allen et al., 2011) for the purpose of a relative contrast between the MBL and free troposphere; however, there were episodes where pollution was transported large distances, resulting in discrete layers of higher $\mathrm{CCN}$ concentrations that may have been entrained into the MBL (this effect is not addressed in the current study).

The potential temperature, $\theta$, and vapour mixing ratio, $q_{v}$, were initialised with an idealised sounding as shown in Fig. 4.

To promote turbulence a random perturbation with maximum magnitude of $\pm 0.1 \mathrm{~K}$ was applied to the initial potential temperature field below the inversion; no perturbation was added above the inversion. The model was also run with interactive shortwave and longwave radiation (Edwards and Slingo, 1996), which was updated every $150 \mathrm{~s}$ model time. Rather than use a set droplet effective radius for the radiative transfer scheme, it was diagnosed from the microphysics scheme, which allows the so-called "Twomey effect" to be accurately modelled. Large-scale divergence was specified to be $3 \times 10^{-6} \mathrm{~s}^{-1}$, which is consistent with both QuikSCAT and WRF simulations for the period in question (Rahn and Garreaud, 2010) and helps to maintain the inversion.

The microphysics scheme used was a two-moment scheme for both cloud water and rain water fields and based on that by Morrison et al. (2005), but with prognostic CCN. In accord with the in situ observations, the representation of the raindrop size distribution within the LEM microphysics scheme was parameterised as an exponential distribution. The rate of warm rain formation was parameterised using the auto-conversion scheme described by Seifert and Beheng (2006). This scheme requires that the cloud drop size distribution is input as a modified gamma distribution in mass and the rain drop distribution be exponentially distributed. Shortcomings of assuming an exponential distribution for rain are acknowledged since, in reality, the larger drizzle drops tend to sediment out of the cloud, resulting in the drizzle having a well-defined "mode" rather than being exponentially distributed (Dearden et al., 2011), and the results here may prove to be sensitive to these assumptions.

In addition to the prognostic model fields for cloud drop number concentration and mass mixing ratio, a parameterisation for the effective radius in stratocumulus clouds (Martin

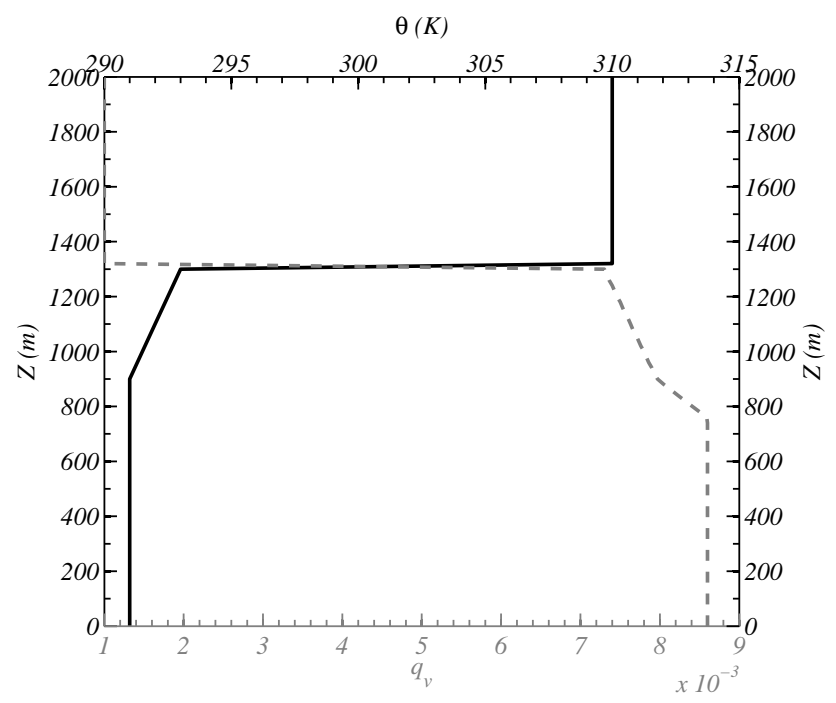

Fig. 4. Initial potential temperature and vapour mixing ratio for the model simulations presented.

et al., 1994) is used to enable the specification of all three parameters in the modified gamma distribution for cloud water.

The microphysics scheme also has a field for prognostic $\mathrm{CCN}$, which interacts with the cloud fields, therefore having consistent sources and sinks. Observational data were used to constrain the $\mathrm{CCN}$ within the model as described in Sect. 3.1.2.

\subsubsection{Gravity wave kinematics}

The gravity wave properties were derived from GOES10 satellite observations of brightness temperature in the thermal infrared. The approximation was made that the brightness temperature was equal to the temperature of the top of the cloud and that the initial lifting (before precipitation occurred) was adiabatic. This allowed us to quantify the wavelength and amplitude of the gravity wave packet.

The observations showed that the wave was monochromatic (Allen et al., 2012), and non-dispersive. Hence, the phase velocity, $v_{\mathrm{p}}=\frac{\omega}{k}$, could be calculated using consecutive images to see how far the wave crests travelled in a time period.

In order to do this we took two consecutive GOES10 satellite images, taken an hour apart, and drew a rectangular box perpendicular to the wave front. We then calculated means and standard deviations of the brightness temperatures as a function of distance perpendicular to the wave front. Figure 5 shows two GOES10 images that depict this procedure, with the rectangles showing the area over which statistics were taken.

The statistics of the wave derived from the two images in Fig. 5 are shown in Fig. 6a and b. A clear wave structure is seen in the fields of brightness temperature, with an amplitude of around $1.0 \mathrm{~K}$ and a wavelength of $\sim 100 \mathrm{~km}$. 


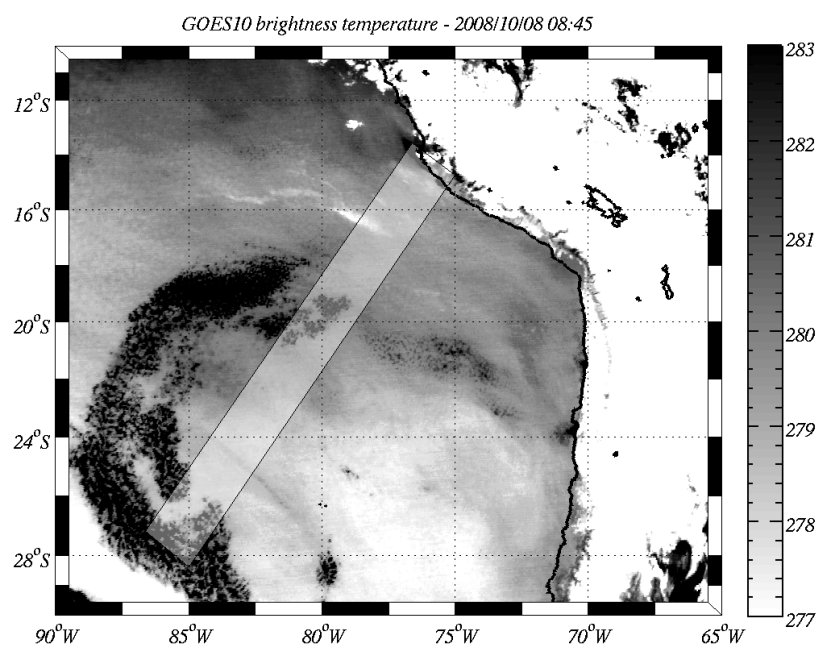

GOES10 brightness temperature - 2008/10108 09:45

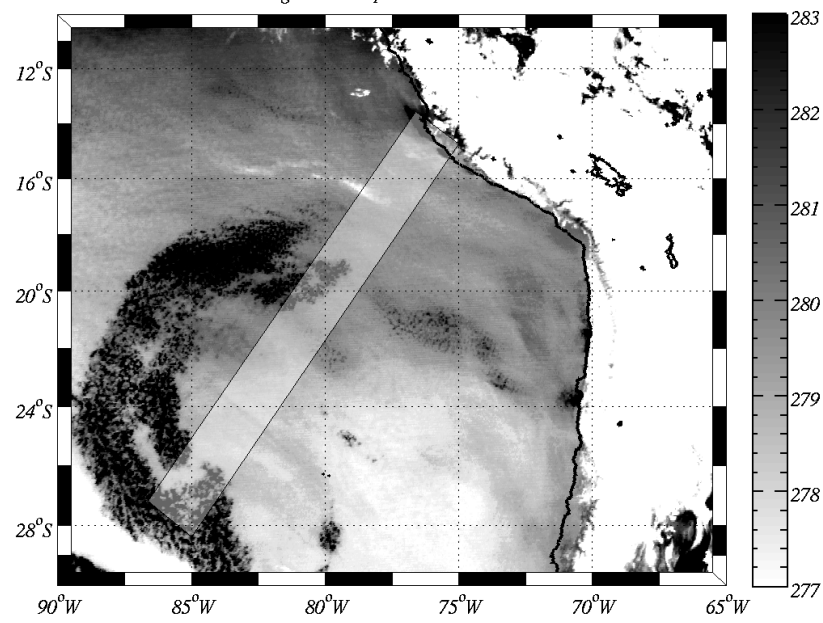

Fig. 5. Gravity waves observed from GOES10 satellite data for images taken at 08:45 and 09:45 GMT. The rectangles shown on each image depict the area over which the statistics of brightness temperature where calculated.

Allen et al. (2012) provided an estimate of the wavelength of $\sim 55 \mathrm{~km}$, although our more rigorous analysis suggests that $\sim 100 \mathrm{~km}$ is a better characterisation. Comparing Fig. 6a and $\mathrm{b}$ it can be seen that the wave has moved around $55 \mathrm{~km}$ in distance from its original location at 08:45 GMT, hence the phase velocity of the wave, $v_{\mathrm{p}} \sim \frac{55 \times 10^{3}}{3600} \sim 15.3 \mathrm{~m} \mathrm{~s}^{-1}$.

In order to convert the difference in brightness temperature to a displacement in altitude we assume that the wave lifting is adiabatic. At $\sim 280 \mathrm{~K}$ the saturated adiabatic lapse rate is approximately $6 \mathrm{~K} \mathrm{~km}^{-1}$, and so this can be used to convert the brightness temperatures to a displacement. Figure $6 \mathrm{c}$ and $\mathrm{d}$ suggest that the amplitude of the wave was around 50 to $100 \mathrm{~m}$, at least for the period shown. In another case (not discussed here) the amplitude of the wave could extend to around 150 to $250 \mathrm{~m}$.

Due to computational constraints, for the majority of runs, our model domain was only $16 \mathrm{~km} \times 16 \mathrm{~km}$ in the horizon- tal. Figure 7 superimposes such a domain on a satellite image, showing it to be considerably smaller than the scale of convective organisation; thus we cannot aim to represent an MCC. Further, the domain is much smaller than the gravity wave wavelength $(\sim 100 \mathrm{~km})$, so we cannot model the passage of the wave across the domain either. Rather, we restrict this study to an investigation of the physics leading to cloud clearing by applying a wave perturbation uniformly across the domain. This perturbation is generated by modulating the subsidence velocity in the model.

The properties of a time-dependent horizontally homogeneous wave that this produces can be derived from the properties of the travelling wave through the relation between phase velocity, $v_{\mathrm{p}}$, wave number, $k=\frac{2 \pi}{\lambda}$, and angular velocity, $\omega=\frac{2 \pi}{T}$, i.e.

$v_{\mathrm{p}}=\frac{\omega}{k}=\frac{\lambda}{T}$;

therefore, we can derive the period of the equivalent timedependent wave to be $T=\frac{\lambda}{v_{\mathrm{p}}} \sim \frac{100 \times 10^{3}}{15.3} \sim 6500 \mathrm{~s}$. There were slight variations in the derived time periods depending on the time of day and location; hence, an average value for the period of the wave, for use in the model, was taken to be $T=5400 \mathrm{~s}$.

Adding this forcing produces an adiabatic cooling to the cloud, which the model microphysics and dynamics respond to. The requirement is that the amplitude at the inversion, $A$, is $150 \mathrm{~m}$ and that this decays to zero at the surface (to satisfy the gravity wave boundary condition). Thus we linearly increased the amplitude of the wave from zero at the surface to $A$ at the height of the inversion:

$z(z, t)= \begin{cases}z+\frac{A z}{z_{i}}\left(\sin \left(\frac{2 \pi\left[t-t_{0}\right]}{T}\right)\right) & \text { if } z \leq z_{i} \\ z+A\left(\sin \left(\frac{2 \pi\left[t-t_{0}\right]}{T}\right)\right) & \text { if } z>z_{i} \\ z \text { if } t<t_{0} \text { or } t>t_{0}+n \times T & \end{cases}$

where $z$ is the altitude, $t$ is time, $z_{i}$ is the height of the inversion, $t_{0}$ is the time when the wave starts, $T$ is the period of the wave, $n$ is the number of cycles of the wave that the cloud is subject to, and $A$ is the wave amplitude. Differentiating Eq. (2) with regard to time yields the velocity

$w(z, t)= \begin{cases}\frac{A z}{z_{i}} \times \frac{2 \pi}{T} \cos \left(\frac{2 \pi\left[t-t_{0}\right]}{T}\right) & \text { if } z \leq z_{i} \\ A \times \frac{2 \pi}{T} \cos \left(\frac{2 \pi\left[t-t_{0}\right]}{T}\right) & \text { if } z>z_{i}, \\ 0 \text { if } t<t_{0} \text { or } t>t_{0}+n \times T & \end{cases}$

where $w$ is the vertical wind to be added to the subsidence forcing in the model.

The gravity wave therefore does not directly affect the small-scale dynamics within the Sc deck, but does so indirectly, through the inhomogeneities brought about by extra condensation and warm rain formation.

A key question is thus: what are the threshold wave amplitudes or number of waves required to produce an irreversible change in the Sc cloud? 

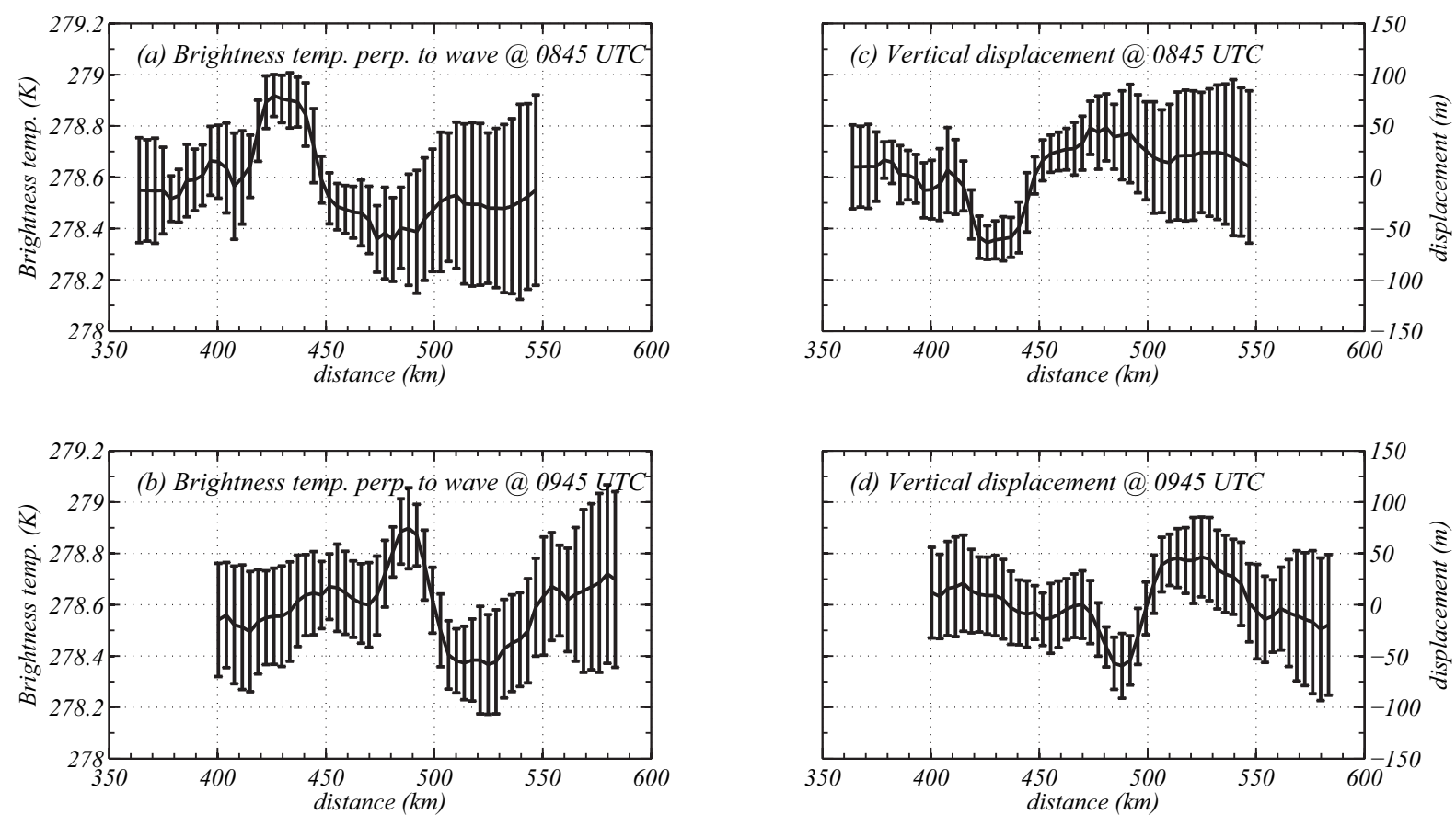

Fig. 6. Statistics of the gravity wave observed from GOES10 satellite data. (a) and (c) are the brightness temperatures and calculated displacements for the left image in Fig. 5 respectively, while (b) and (d) are the same but for the right image in Fig. 5. The solid lines are means and the error bars depict 1 standard deviation, either side of the mean.

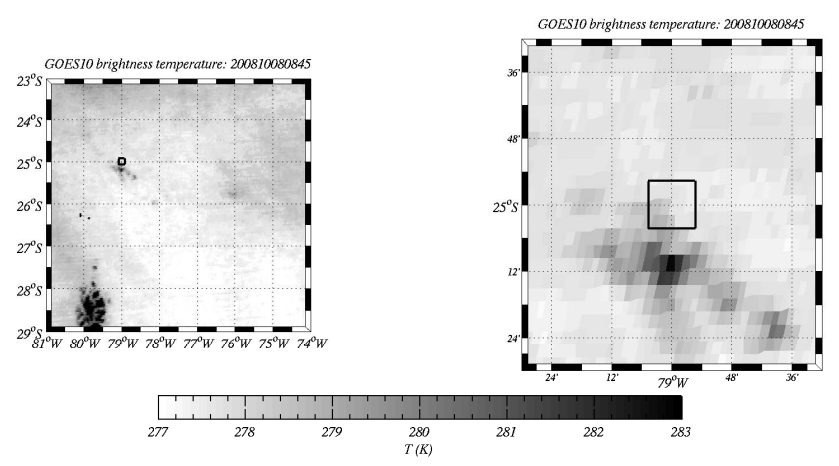

Fig. 7. Figure showing the scale of the model simulations. Left shows the domain depicted on a satellite image of GOES10 brightness temperatures that extends $6-7^{\circ}$ in latitude and longitude, while the right image shows the domain depicted on a satellite image that extends $1^{\circ}$ in both latitude and longitude.

\subsubsection{CCN activation and parcel modelling}

The purpose of this section is to provide details on how observations were used to constrain the $\mathrm{CCN}$ inputs to the LEM. CCN activation within the LEM microphysics scheme used in this study follows the Twomey (1959) approach, where the number of CCN activated depends on the peak updraft velocity at cloud base. In fact we used the more common approximation found in Rogers and Yau (1989):
$N_{\mathrm{CCN}}=0.88 \times C^{2 /(2+k)} \times\left(70 \times w^{3 / 2}\right)^{(k /(2+k))}$,

where $N_{\mathrm{CCN}}$ is the drop concentration $\left(\mathrm{cm}^{-3}\right)$ at cloud base, $w$ the updraught speed in $\mathrm{m} \mathrm{s}^{-1}$ and $C\left(\mathrm{~cm}^{-3}\right)$ and $k$ are constants describing the supersaturation activity of the $\mathrm{CCN}$ $N_{\mathrm{CCN}}=C s^{k}$, where $s$ is the supersaturation in percent. This approach requires the constants $C$ and $k$, which were derived by applying a parcel model (described below) to aerosol data taken from the BAe-146 FAAM aircraft measurements presented in Allen et al. (2011).

Aerosol size distributions in the MBL over the SEP were measured on board the BAe-146 Facility for Airborne Atmospheric Measurements (FAAM) aircraft using an scanning mobility particle sizer (SMPS) and a passive cavity aerosol spectrometer probe (PCASP) as described by Allen et al. (2011). The chemical composition of the aerosol was measured with a Aerodyne Aerosol Mass Spectrometer (AMS) and found to be predominantly sulfate internally mixed with a small amount of organics.

In order to observationally constrain CCN in the LEM, quad-log-normal fits to the SMPS and PCASP data (see Allen et al., 2011, which are reproduced in Table 1) were used as input to the ACPIM, bin-microphysics, parcel model (see Connolly et al., 2009, 2012) and the model was run for 10 different updraft speeds $-w=$ $[0.01,0.03,0.05,0.10,0.15,0.20,0.25,0.50,0.75,1.00]-$ to 

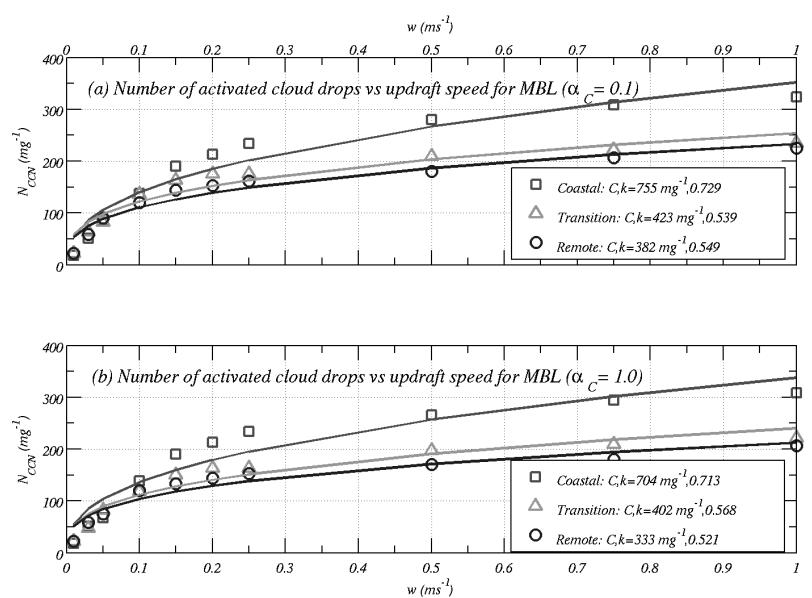

Fig. 8. Results from the parcel model simulating the number of activated cloud drops as a function of updraft velocity. (a) shows calculations when a mass accommodation coefficient $\alpha_{\mathrm{C}}=0.1$ and (b) shows the same but for $\alpha_{\mathrm{C}}=1.0$. In each case, squares are for the coastal region, triangles are the for transition region and circles for the remote region. Fitted values for the constants $C$ and $k$ in Eq. (4) are shown in the legend.

determine the dependence of $\mathrm{CCN}$ number concentration on updraft speed. Following this, Eq. (4) was fitted to the model output, using non-linear regression, to find the constants $C$ and $k$. This was repeated for each of the three regions described by Allen et al. (2011): coastal, transitional and remote. We also investigated the dependence of the results on the mass accommodation coefficient, $\alpha_{\mathrm{C}}$, which is poorly constrained at the present time, thus making a total of 60 runs for this analysis. The initial conditions for the ACPIM parcel modelling were pressure, $P=950 \mathrm{mbar}$; temperature, $T=11^{\circ} \mathrm{C}$; and relative humidity, $\mathrm{RH}=0.95$. The model was run for a total ascent of $200 \mathrm{~m}$, at which point the number of activated cloud drops was determined.

The results of the ACPIM parcel modelling are shown in Fig. 8a and b, which shows only a small sensitivity to $\alpha_{\mathrm{C}}$ in the range $0.1 \leq \alpha_{\mathrm{C}} \leq 1.0$. As expected, the number of $\mathrm{CCN}$ decreases with increasing distance from the coast, although there is little drop-off in CCN concentrations when moving from the transition region to the remote region. In the context of this study the coastal CCN concentrations will be referred to as "high", transitional will be referred to as "medium" and remote will be referred to as "low". It is recognised that these $\mathrm{CCN}$ values do not represent a large variation in $\mathrm{CCN}$ number concentration; nevertheless, the descriptors, high, medium and low are relevant in the context of this study. All runs, unless explicitly stated, used medium $\mathrm{CCN}$ concentrations.

The LEM was used to investigate the effect of the imposed wave on the dynamics and microphysics of the stratocumulus clouds. A number of model runs based on the methodol-
Table 2. A summary of the sensitivity tests performed with the LEM.

\begin{tabular}{ll}
\hline CNTRL & Control simulation - no gravity wave, medium CCN \\
\hline GW150 & Same as control, but with 150 m wave at 05:00 LT \\
GW200 & Same as control, but with 200 m wave at 05:00 LT \\
GW250 & Same as control, but with 250 m wave at 05:00 LT \\
GW300 & Same as control, but with 300 m wave at 05:00 LT \\
\hline GW150CCNL & 150 m amplitude wave with low CCN \\
GW300CCNH & 300 m amplitude wave with high \\
\hline GW150x2 & Same as control but with 2 $\times 150 \mathrm{~m}$ wave at 05:00 LT \\
GW150x3 & Same as control but with 3 $\times 150 \mathrm{~m}$ wave at 05:00 LT \\
GW150x4 & Same as control but with $4 \times 150 \mathrm{~m}$ wave at 05:00 LT \\
\hline GW150x4_NR & Same as GW150x4 and no warm rain \\
\hline GW150_s3 & Single 150 m wave occurring at 08:00 LT \\
GW150_s4 & Single 150 m wave occurring at 09:00 LT
\end{tabular}

ogy described in Sects. 3.1, 3.1.1 and above were performed, which, for completeness, are listed in Table 2.

\section{Results - LEM simulations}

Here we present results from the LEM simulations to show the sensitivity to the forcing imposed by gravity waves. The results are organised into eight main sections, dealing with the effects of the amplitude of the gravity waves on the response of the modelled MBL Sc; the effect of including multiple waves of amplitude, $A=150 \mathrm{~m}$; the effect of wave timing and the temporal evolution of the cloud, specifically waves occurring at night and during daytime; the effects of warm rain and $\mathrm{CCN}$; and cloud-top entrainment and the grid spacing/domain size.

Firstly, we present images of the modelled LWP for two of the simulations: one without any imposed gravity wave forcing and one with a single $150 \mathrm{~m}$ amplitude gravity wave initiated at 05:00 LT. Figure 9 shows the results of these two simulations and shows that the effect of the wave is to firstly increase the LWP (Fig. 9a and e), following which the cloud clears and breaks up in the downward part of the wave (Fig. 9b and f). However, the LWP soon recovers almost to previous values (Fig. 9c and g), but then starts to break up towards the end of the simulation (Fig. 9d and h). Although there are similarities to the satellite images presented in Fig. 3, it is apparent that the modelled clouds take much longer to clear (some $8 \mathrm{~h}$ after the occurrence of the wave), whereas in the observations, clearance occurred almost immediately after the passage of the wave. The model results in this case are therefore not consistent with the observations.

\subsection{Effect of wave amplitude}

As there was some variability in the amplitude of the observed gravity waves, we have looked at the effect of wave amplitude on the MBL Sc. Figure 10 shows the results of this 
(a)nowave @05:15 local
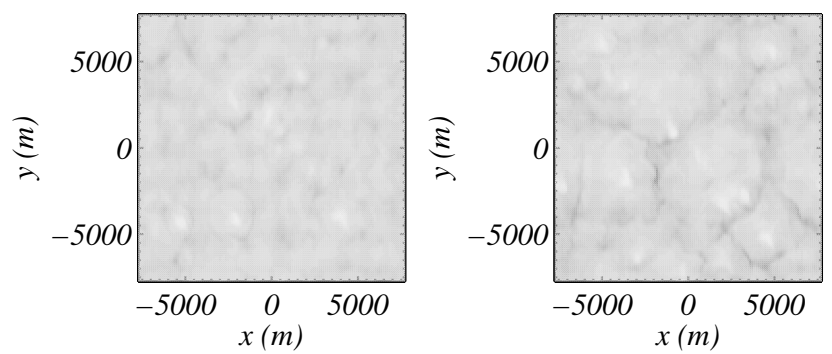

(c)nowave@08:30local

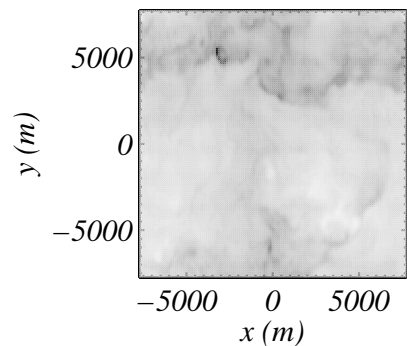

(d)nowave @ 15:00 local

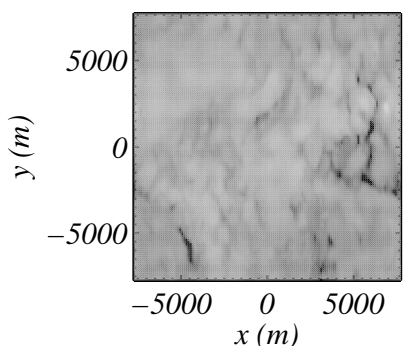

(e) 150mwave@05:15 local

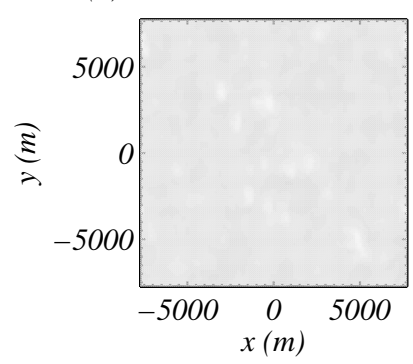

(f) 150 mwave @ 06:00local

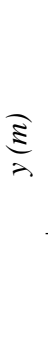

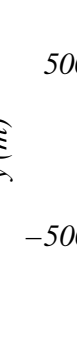

(g) 150 mwave@08:30local

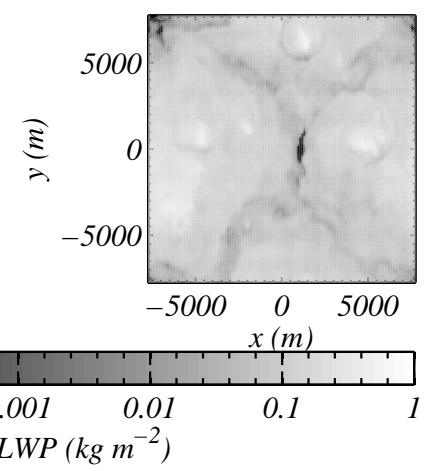

(h) 150mwave@15:00local

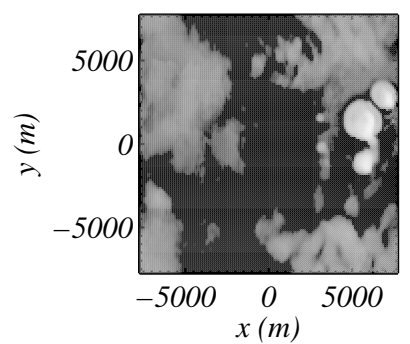

Fig. 9. Snapshots of the LWP modelled for a case without an imposed gravity wave (a-d) and with an imposed gravity wave with amplitude, $A=150 \mathrm{~m}$ (e-h). (e) shows the cloud layer being lifted and the associated increase in LWP, whereas (f) shows the layer descended in the trough of the wave. (d) and (h) show that the effect of the wave is to break up the cloud layer.

set of simulations. It is seen that the case without any gravity waves results in almost completely overcast conditions, whereas the cases with waves all result in a slow clearing of the cloud, some $8 \mathrm{~h}$ after the occurrence of the wave. While there are some subtleties, it is apparent in these simulations that wave amplitude does not have an appreciable effect on the clearing of the cloud. However, it is noteworthy that the $300 \mathrm{~m}$ wave results in the MBL Sc taking longer to fill in after the occurrence of the wave at $\sim 06: 50$ LT. It may therefore be that waves with higher amplitudes than $300 \mathrm{~m}$ would result in a rapid clearing of the cloud; however, such high amplitudes were not observed and are deemed to be unrealistic.

\subsection{Effect of multiple waves}

It is clear from the GOES10 imagery that a gravity wave train can contain multiple peaks and troughs. Hence we decided to examine the sensitivity of the modelled MBL Sc to the number of gravity wave oscillations by including 1,2, 3 or 4 successive cycles of the wave. Figure 11 shows a comparison of modelled LWP, comparing a case with no gravity waves to a case with 3 successive gravity waves. In this figure, panels (e), (f) and (g) show times in the downward moving part of the wave, and hence show the cloud breaking up after an initial increase in LWP prior to this. When comparing these to the equivalent times without a gravity wave $(\mathrm{a}, \mathrm{b}$ and $\mathrm{c})$ it can be seen that each time a wave occurs, it results in an increase in the amount of broken cloud. Figure $11 \mathrm{~d}$ and $\mathrm{h}$ show the cloud at the end of the model simulations, long after the waves occurred, where it is clear that the case with 4 waves has resulted in a significant amount of clearing of the cloud layer.

To look at the effect of multiple numbers of wave in more detail we present the cloud cover percentage time series in Fig. 12. In this figure it can be seen that the simulation with two waves results in a slight clearing of the cloud layer at about 08:10 LT, which takes a while to fill back in, before clearing again in a similar way to the single-wave cases in Fig. 10. However, the simulations with both 3 and 4 waves are significantly different. The case with 3 waves results in a sudden change in the total cloud coverage to about $60 \%$, which then decreases to almost zero at the end of the simulation, whereas the case with 4 waves results in an even more dramatic change in the total cloud cover; however, cloud coverage then increases slowly as the simulation progresses. 


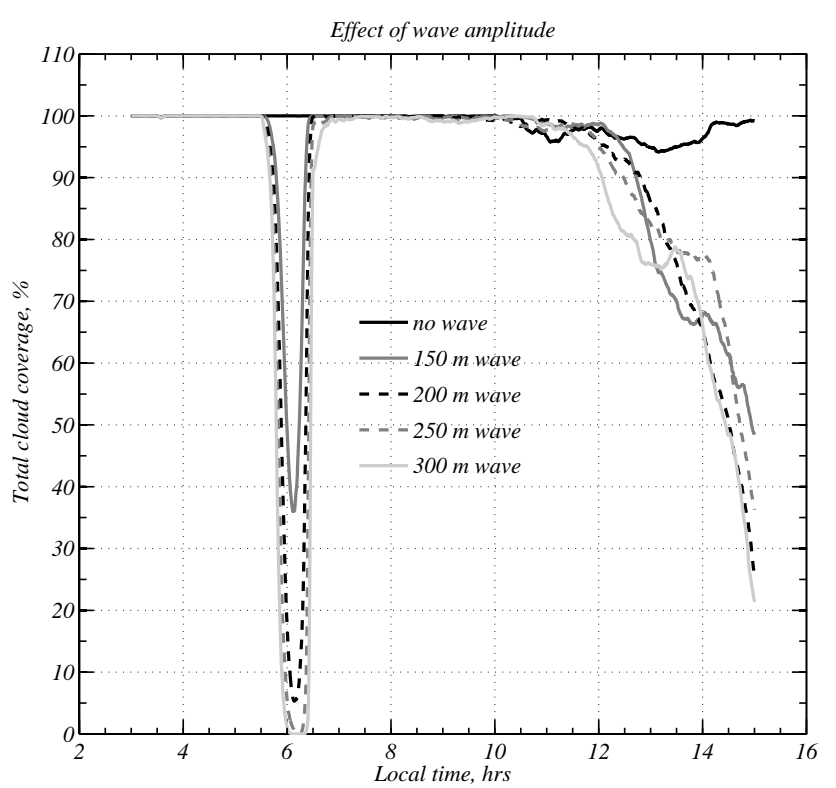

Fig. 10. Time series of the total cloud coverage from the LEM in percent for gravity waves with different amplitudes, $A$. It is shown that the case without a gravity wave leads to overcast conditions, while all other cases lead to a reduction in cloud coverage - albeit some $8 \mathrm{~h}$ after the wave.

\subsection{Effect of timing of the wave}

To attempt to answer the question of whether the cumulative effect of multiple waves was important or whether it is the timing that is important we ran two simulations using single $150 \mathrm{~m}$ waves but altered the time of day at which they occurred: (i) the time at which the 3rd wave occurred in the 3and 4-wave simulations "single 3rd wave" and (ii) the time at which the 4th wave occurred in the 4-wave simulation "single 4th wave". The LWP fields from these simulations are shown in Fig. 13. Figure 13a and e show the LWP before any gravity wave perturbations have been applied, whereas Fig. 13b shows a time just after the wave in the single 3rd wave simulation; Fig. $13 \mathrm{f}$ is the same time but for the single 4 th wave simulation. Figure 13g shows the LWP field at a time just after the wave in the single 4th wave simulation. By this time both simulations display broken cloud, the amount of which increases towards the end of the simulation (Fig. 13d and h). Thus here it is apparent that the timing of the wave is crucial to its effect on the MBL Sc.

The results of the simulations shown in Fig. 13 are compared to the "no wave" case and summarised in terms of total cloud cover in Fig. 14. Here it is apparent that the single 3rd wave simulation does not result in a dramatic reduction in total cloud cover, but it does take time to fill back in to $100 \%$, before breaking up again in a similar way to all single-wave cases. However the single 4th wave case does result in a clear reduction in cloud coverage, although not quite as dramatic as the case that included four cycles of the wave. There is no strong evidence for a change in convective regime, like in Fig. 12. It is therefore apparent that both the timing and the number of waves affect cloud clearing. A point worth noting is that there was more drizzle in the case with multiple waves, and this had an impact on the development of weak cold pools in the MBL, which increased convective instability.

Figures 14 and 15a suggest that at 09:00 LT the boundary layer is still strongly coupled to the surface fluxes of moisture; this is why the single 3rd wave case does not result in a clearing of the cloud layer. However, by approximately 11:00 LT (or just after) it appears that the boundary layer becomes decoupled from the moisture fluxes. The decoupling of the cloud layer from the lower level fluxes may be demonstrated by a vertical profile of the variance of vertical velocity, $\overline{w^{\prime} w^{\prime}}$.

Figure $15 \mathrm{a}$ and $\mathrm{b}$ show the variance of the vertical velocity for five model simulations: the no wave case, the single 1st wave case, the case with $4150 \mathrm{~m}$ waves and the single 3rd wave and single 4th wave case. Figure 15a shows the variance of vertical velocity at 09:00 LT showing that $\overline{w^{\prime} w^{\prime}}$ is reasonably high in the cloud region for all cases except the simulation with 4 wave cycles. It should be noted that at 09:00 LT in both the simulation with 4 wave cycles and the single 3rd wave case wave subsidence is occurring, which effectively lowers the inversion by $150 \mathrm{~m}$.

Figure $15 \mathrm{~b}$ shows the corresponding variance of vertical velocity at 12:00 LT and shows a significant reduction in the velocity variance for all simulations, with a weighting towards higher variances near the surface, thus signalling the decoupling of the cloud from the surface fluxes. It is noticeable that both the simulation with 4 waves and the single 4th wave case have lower variance of vertical velocity in the region $600<Z<1200 \mathrm{~m}$ than the other cases at this time. Although not shown here, analysis of the variance of vertical velocity at the end of the simulations shows that, of all of the simulations, the case with 4 waves leads to the highest variances throughout the depth of the boundary layer. Although this demonstrates some degree of coupling, it is not homogeneous across the model domain and is more similar to $\mathrm{Cu}$ type convection.

\subsection{Evolution of cloud throughout the day}

Figure 16 shows the evolution of cloud-top and cloud-base altitude from a simulation with no wave and three simulations with a $150 \mathrm{~m}$ that occurred at the time of the $1 \mathrm{st}, 3 \mathrm{rd}$ and 4th wave in the 4-wave simulation. These are referred to as the single 1 st wave, single 3 rd wave and single 4 th wave simulations respectively. It can be seen that the thickness of the cloud layer, in all simulations, is reduced throughout the day, due to absorption of solar radiation and the resultant warming of the boundary layer, such that at the end of the simulations the cloud layer is only $\sim 100 \mathrm{~m}$ thick. 
(a)nowave @07:15 local
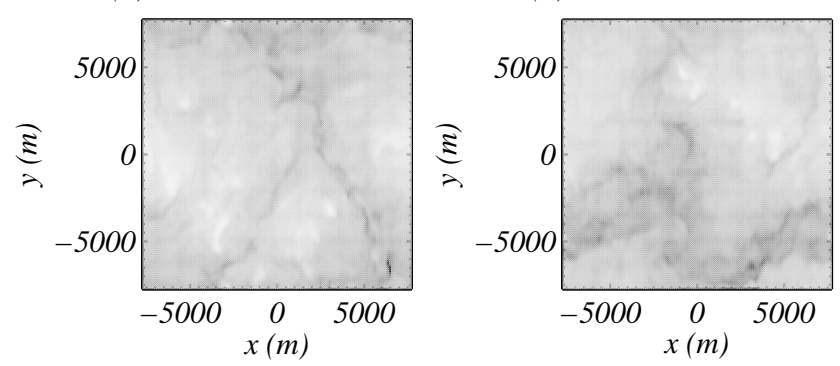

(c)nowave@10:15 local

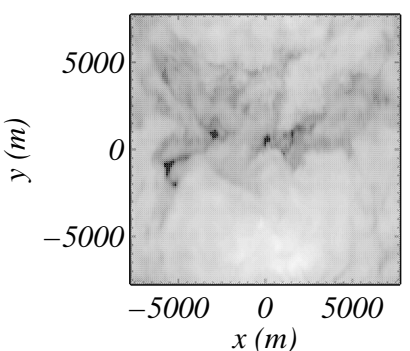

(d)nowave@15:00 local

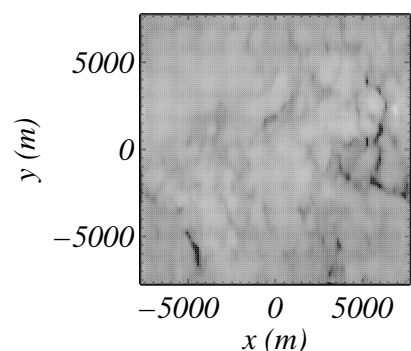

(e)4x150mwaves@07:15

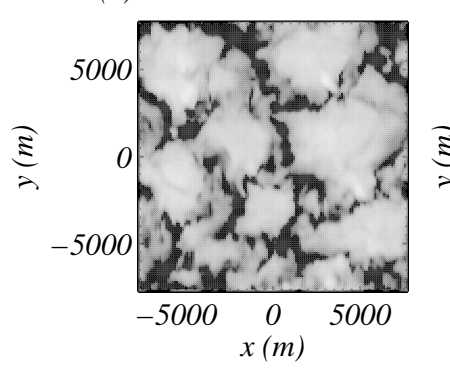

(f)4x150mwaves @08:45

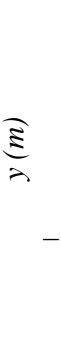

(g)4x150mwaves@10:15

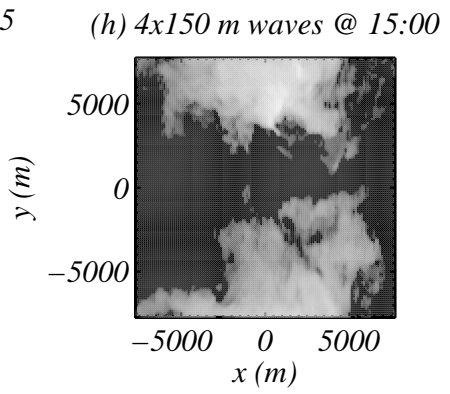

Fig. 11. Same as Fig. 9 except the comparison is for no wave vs. 4 successive gravity waves with amplitude, $A=150 \mathrm{~m}$. The cases with 4 successive waves are shown in $(\mathbf{e}-\mathbf{h})$. $(\mathbf{e}-\mathbf{g})$ show conditions in the downward part of the last 3 waves respectively, whereas (h) shows the end of the simulation.

It is shown that cloud-top altitude after the single 3rd wave and single 4th wave simulations is lower than the no wave case. This is similar for the cloud-base altitude. In both cases the difference is considerably greater than in the single 1st wave case. The lowering of the cloud top is an indicator of cloud-top entrainment; hence, these results suggest that there is not much enhancement of cloud-top entrainment in the single 1st wave case. This is a qualitative demonstration that entrainment is enhanced in the cases with imposed gravity waves and that the timing of the wave is crucial to the effect that cloud-top entrainment has on the evolution of the cloud.

\subsection{Effect of warm rain formation}

The importance of multiple successive waves may suggest that each time the cloud layer is lifted, the resulting warm rain acts to reduce the LWP resulting in a cumulative effect on the clearing of the cloud. Warm rain generation was indeed seen in the model fields each time the cloud layer was lifted; however, this rarely reached the surface in the model, as it evaporated during its descent. In order to ascertain the importance of the warm rain process we ran an additional model simulation with the warm rain auto-conversion scheme switched off for the case with 4 successive waves.
The results of this are summarised in Fig. 17. Here it can be seen that both cases result in a clearing of the MBL Sc, therefore suggesting that the main process responsible for clearing the cloud is not the warm rain process itself. However, we note that the simulation with warm rain results in a change in convective regime later in the simulations (as shown by the more rapid increase in total cloud coverage near the end of the simulation). Other analyses of the variance of vertical velocity (not shown) indicate that the " $4 \times 150$ m wave" case with rain has much higher variances in the cloud layer at the end of the simulations compared to the same case without warm rain. The reason for this is that the evaporation of rain below cloud destabilises the boundary layer so that the cloud layer has better coupling to the surface fluxes of moisture. Also worthy of note is that the simulation with warm rain results in the lowest cloud coverage in each downward part of the wave, which is as expected since warm rain removes total water from the cloud layer.

\subsection{Influence of $\mathrm{CCN}$ concentration}

It is interesting to investigate whether $\mathrm{CCN}$ concentrations play a role in the clearing of the cloud. POCs were observed to form preferentially in the transition and remote region and 


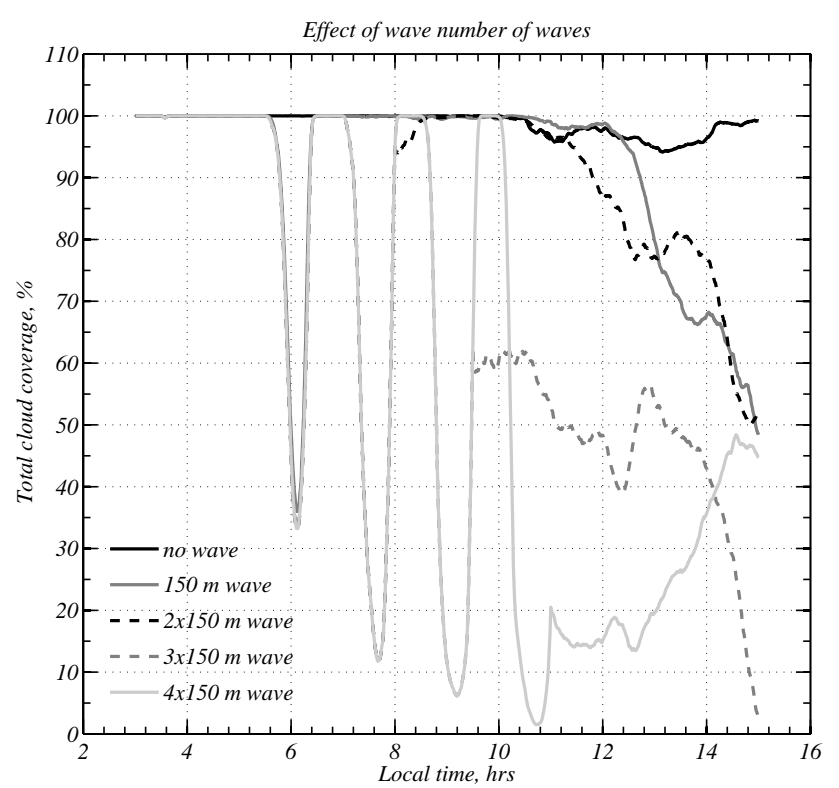

Fig. 12. Similar to Fig. 10 but comparing the effect of different numbers of gravity wave. It is seen that the cases with both 3 and 4 waves lead to a dramatic reduction in total cloud coverage.

CCN concentrations for all three regions are described in Sect. 3.1.2 and shown in Fig. 8. To investigate the role of $\mathrm{CCN}$, two additional simulations were performed, both including warm rain processes. One was a $300 \mathrm{~m}$ wave with high CCN and the other was a $150 \mathrm{~m}$ wave with low CCN. These were chosen to demonstrate whether (i) high $\mathrm{CCN}$ could suppress the slow clearing of the cloud that occurred $8 \mathrm{~h}$ after the wave (Fig. 10) and whether (ii) low CCN could lead to additional clearing of the cloud due to warm rain.

Figure 18 (top) shows the time series of total cloud cover for these simulations. The results show that the $300 \mathrm{~m}$ wave with high CCN results in a cloud with almost $100 \%$ cloud coverage. This is in contrast to the simulation with a $300 \mathrm{~m}$ wave (and medium $\mathrm{CCN}$ ), which resulted in a clearing of the cloud. The reason for this is that the case with higher $\mathrm{CCN}$ resulted in more cloud-top radiative cooling (because the cloud droplets were smaller and more numerous), an effect that was able to maintain the cloud coverage at higher values due to additional condensation.

The simulation with a $150 \mathrm{~m}$ wave and low $\mathrm{CCN}$ failed to clear the cloud. More warm rain was produced in this case than the simulation with a $150 \mathrm{~m}$ wave and medium $\mathrm{CCN}$, which resulted in lower cloud coverage at 11:00 LT; however, the cloud coverage then recovered, presumably because this moistened and cooled the air below the cloud and resulted in a more coupled boundary layer. Hence, it appears that CCN do play an important role in the clearing of the cloud. The intermediate $\mathrm{CCN}$ values away from the coast are more likely to result in a clearing of the cloud than both the higher $\mathrm{CCN}$ values close to the coast and the lower $\mathrm{CCN}$ values away from the coast. Although the $\mathrm{CCN}$ variability within the VOCALS dataset was higher than that taken from comparing the means from the three regions (coastal, transitional and remote), it is encouraging that use of observationally constrained CCN within the LEM is able to provide insights into some of the reasons why the clearing of cloud occurs preferentially in the transition region. It is also likely that boundary layer height plays an important role in the clearing of the cloud; however, this effect is not investigated here.

Figure 18 (bottom) shows the time series of the domainaveraged LWP for the CCN simulations. It can be seen that LWP increases during the crest of the wave, decreases during the trough and then increases to values that are below those seen in the no wave case. Also evident is that higher CCN results in higher LWP initially, but later in the simulations the opposite is true (e.g. compare " $150 \mathrm{~m}$ wave" with " $150 \mathrm{~m}$ wave low aerosol" and "300 m wave" with " $300 \mathrm{~m}$ wave high aerosol").

\subsection{Effect of cloud-top entrainment}

In order to probe whether entrainment of dry air from aloft may be responsible for cloud clearance, we initialised a passive tracer in the model, set to 1.0 above the inversion and zero below the inversion (Fig. 19a). Figure 19b shows the horizontal mean of the tracer field in the model at 12:00 LT. This shows some mixing of the tracer from above the inversion into the boundary layer for all model runs.

Interestingly, the run with one $150 \mathrm{~m}$ gravity wave occurring early in the morning has a tracer distribution that is almost the same as the case without any wave; hence the single, early gravity wave does not cause any additional mixing. When $4 \times 150 \mathrm{~m}$ waves are used for the forcing, there is much more mixing of air above the inversion into the cloud layer. In addition, a similar effect happens when we use a single $150 \mathrm{~m}$ gravity wave that occurs later in the day (single 4th wave). Therefore, the tracer results suggest that it is the mixing in to the cloud of warm, dry air from above the inversion that causes the rapid evaporation of the cloud shortly after the wave. The eddies responsible for the mixing of dry air into the cloud were resolved in the model wind field, as can be seen in the variance of the vertical velocity (Fig. 15), and were a result of latent heating creating more energetic thermals that were able to break through the inversion.

\subsection{Effect of grid spacing and domain size}

Bretherton et al. (1999) suggest that, at the resolutions used in our study, we may potentially overestimate entrainment by $\sim 50 \%$. Therefore, in order to demonstrate that our findings are robust, we test the effect of increasing the spatial resolution by a factor of 2 in the vertical and horizontal $(\Delta x, y=$ $60 \mathrm{~m}, \Delta z \sim 10 \mathrm{~m}$ ). We performed two high-resolution simulations: one without a gravity wave and one with a single, 
(a) wave (time of $3 r d$ ) @ 07:15 (b) wave (time of $3 r d$ ) @ 08:45

(c) wave (time of $3 \mathrm{rd}$ ) @ 10:15

(d) wave (time of $3 r d$ ) @ 15:00
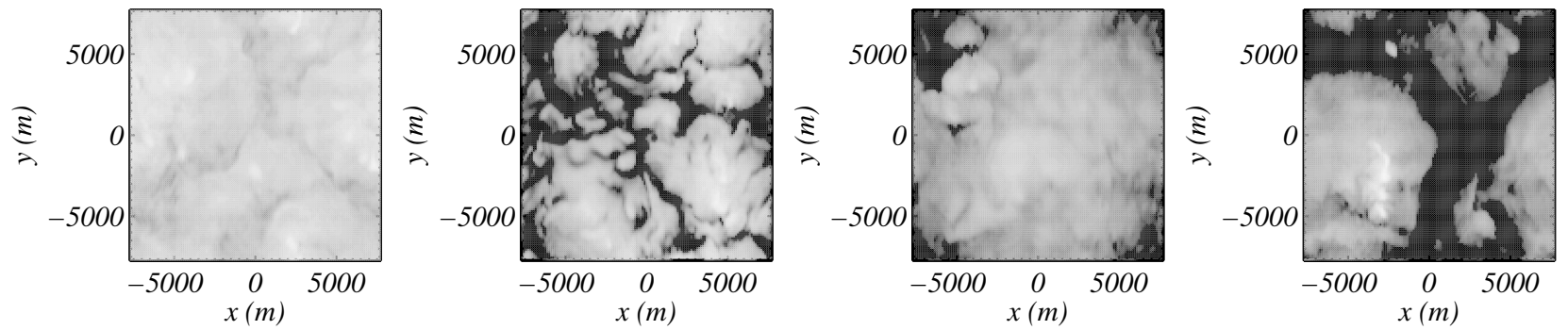

(e)wave (time of 4th) @07:15

(f)wave (time of 4th) @ 08:45

(g) wave (time of 4th) @ 10:15

(h)wave (time of 4th) @ 15:00
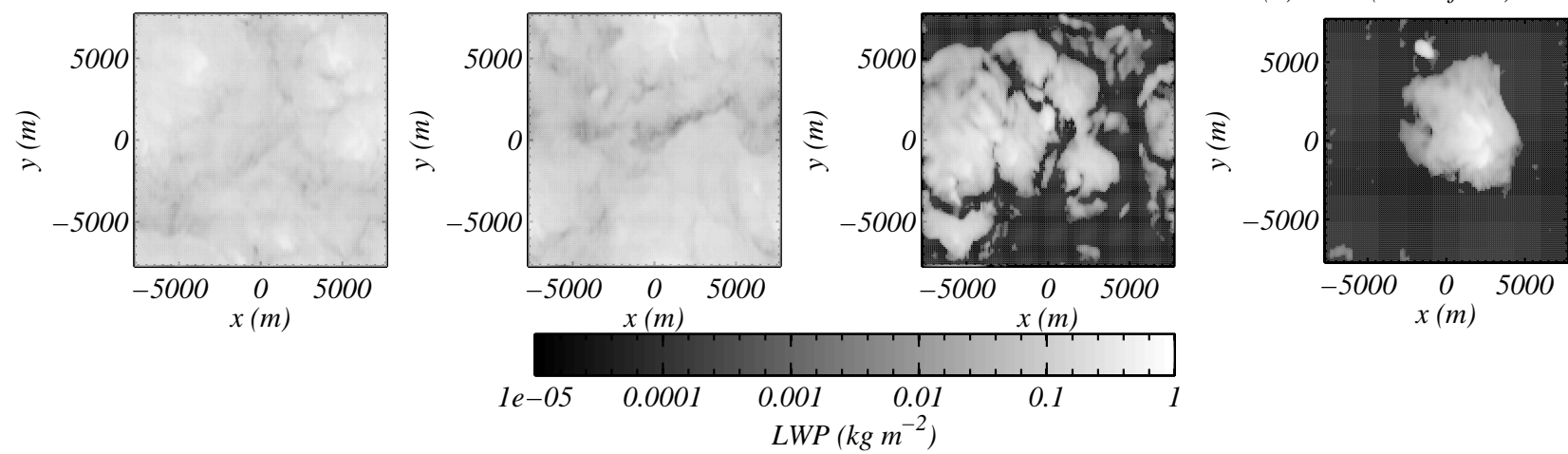

Fig. 13. Same as Fig. 9 except the comparison is for a single $150 \mathrm{~m}$ amplitude wave occurring before sunrise vs. a single $150 \mathrm{~m}$ gravity wave with the same amplitude occurring at the same time as the last wave in the $4 \times$ gravity wave case.

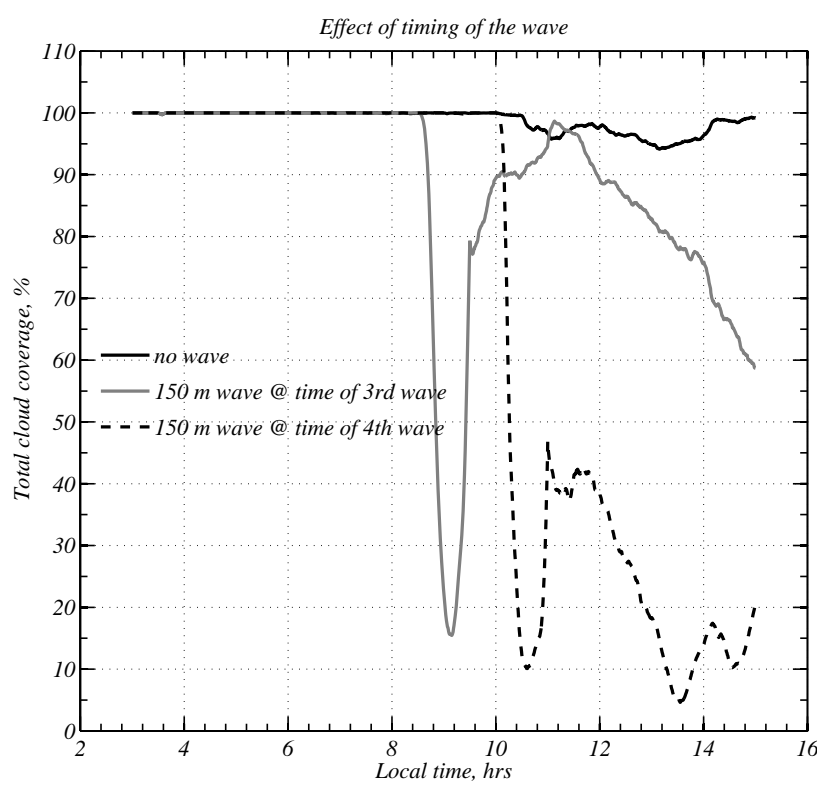

Fig. 14. Similar to Fig. 10 but comparing the effect of waves occurring later in the day. It can be seen that the later the wave occurs the more dramatic the clearing of the cloud layer is.
$150 \mathrm{~m}$ wave occurring at the time of the 4 th wave (single 4 th wave).

Figure 20a-c show the LWP for the high-resolution runs both before and after the gravity wave. It is clear that the cloud coverage is reduced most in the case with the gravity wave, a result that is consistent with the lower-resolution simulations (Fig. 13e-h). This consistency is further demonstrated by the total cloud cover (Fig. 21). It is notable that the amount of clearing taking place after the gravity wave (Fig. 21 grey solid line) is indeed slightly lower for the highresolution case than the control (Fig. 14, black dashed line), suggesting that the entrainment rate is indeed lower in the high-resolution case. Nevertheless, the same effects are still evident in these high-resolution cases.

Feingold et al. (2010) demonstrated that cloud variability results from interactions between cellularisation, precipitation and mesoscale circulations. To test whether our results are sensitive to the choice of domain size, we performed an additional two simulations: one without a gravity wave and one with a gravity wave occurring at the time of the 4th wave (single 4th wave). Each of the large-domain runs had $\Delta x, y=120 \mathrm{~m}, \Delta z \sim 20 \mathrm{~m}$ with the number of grid points in the horizontal set to $512 \times 512$, an extent of $60 \times 60 \mathrm{~km}^{2}$. The liquid water path for these runs is shown in Fig. 20d-f, where 
(a) Time=9:00 (coupled BL)

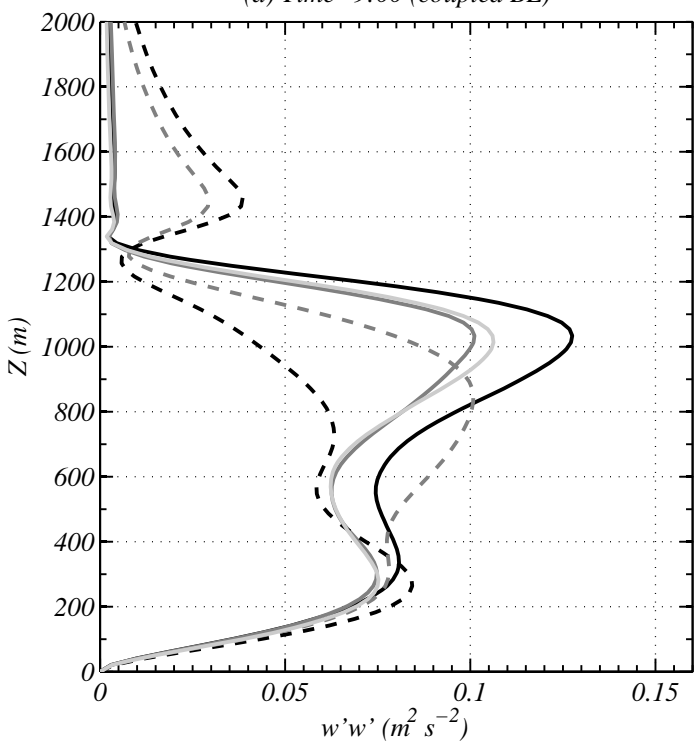

(b) Time $=12: 00$ (decoupled BL)

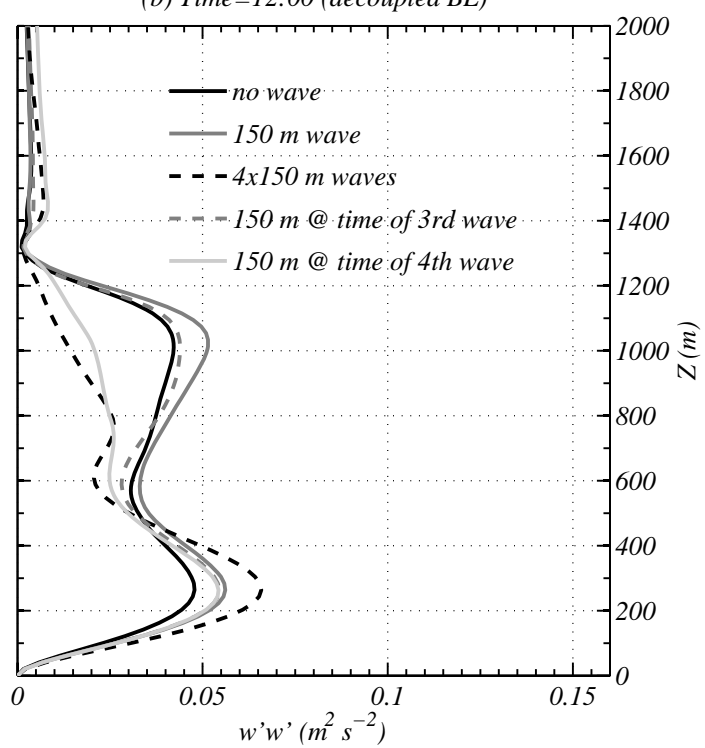

Fig. 15. Variance of vertical velocity throughout the model domain in simulations with no wave; four consecutive cycles of a $150 \mathrm{~m}$ wave "4 × 150 m waves" a $150 \mathrm{~m}$ wave occurring at different times (" $150 \mathrm{~m}$ wave"; " $150 \mathrm{~m}$ wave @ time of 3rd wave" and " $150 \mathrm{~m}$ wave @ time of 4th wave"). (a) shows the variance at 09:00 LT and (b) shows it at approximately 12:00 LT.

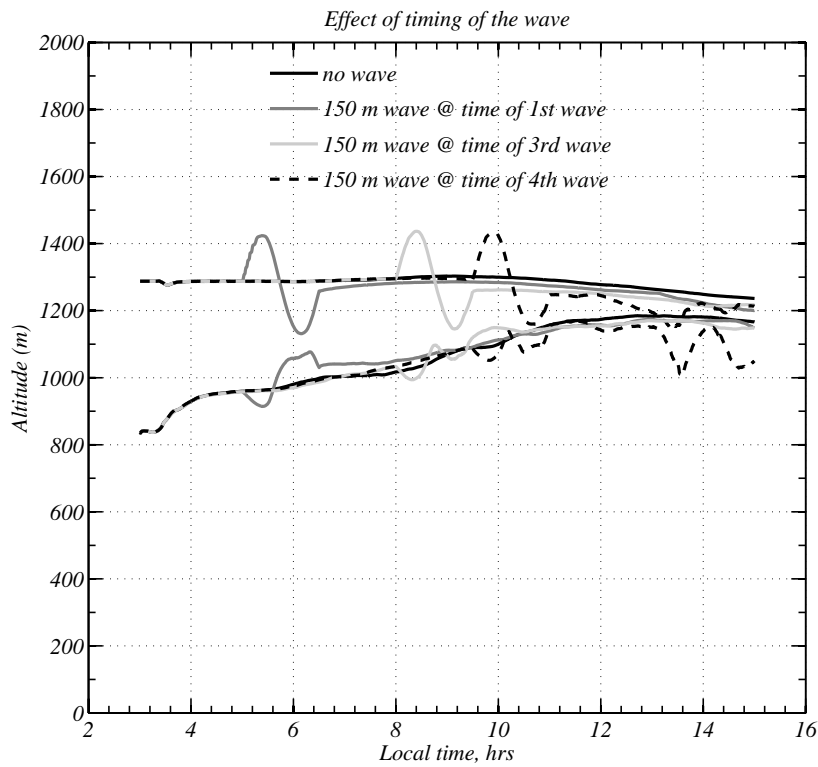

Fig. 16. Shows the evolution of average cloud-top and cloud-base heights for a simulation with no wave and three simulations with a $150 \mathrm{~m}$ wave that occurred at the time of the $1 \mathrm{st}$, 3rd and 4th wave in the 4-wave simulation: single 1st wave, single 3rd wave and single 4 th wave respectively.

it is demonstrated that the case with a gravity wave clears the cloud more effectively than the case without. However, it is evident that the case without a gravity wave also leads to significant cloud clearance (Fig. 20e).

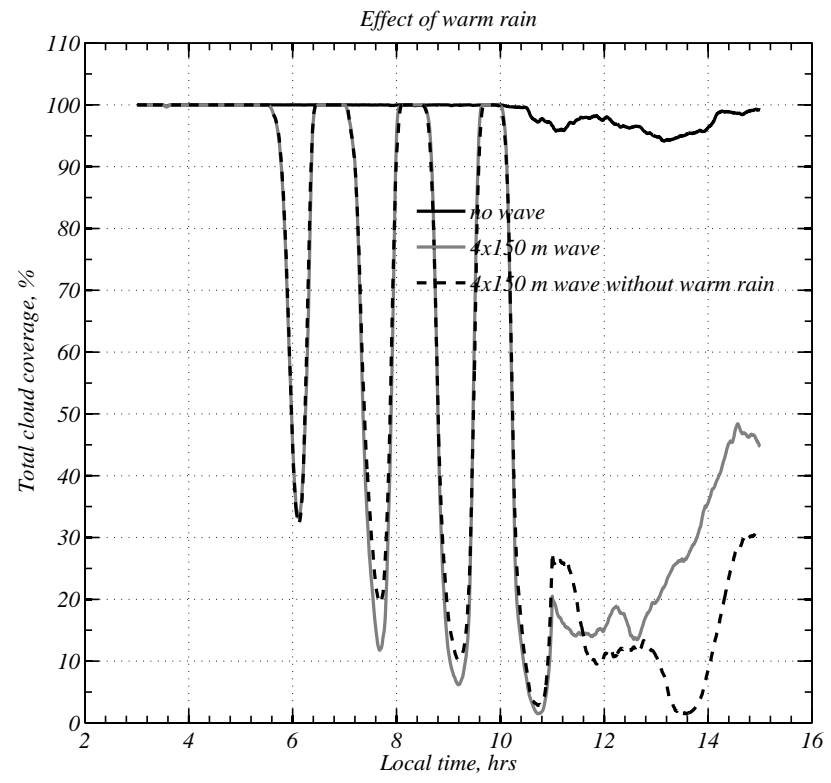

Fig. 17. Similar to Fig. 10, but comparing the effect of having warm rain switch on or off in the model microphysics scheme. Very little difference is evident.

Figure 21 (black and grey dashed lines) shows the total cloud coverage for the large-domain runs. It is apparent that the case without a gravity wave starts to break up slowly some time after 10:00 LT. This is due to the greater variability within the larger domain, which leads to small regions of convergence and associated interactions, as described by 

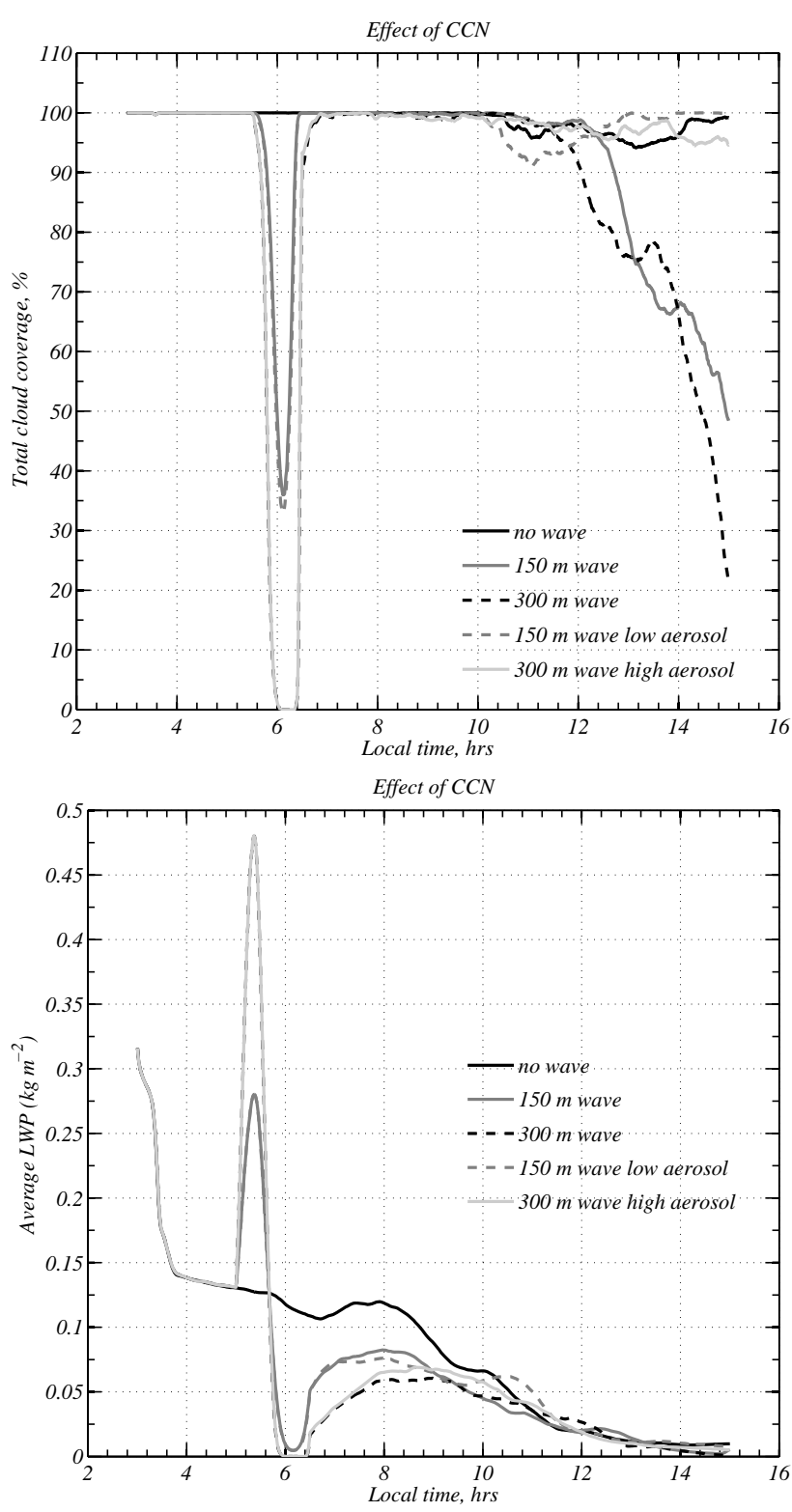

Fig. 18. Top: similar to Fig. 10 but looking at the effect of having low or high CCN. In the $300 \mathrm{~m}$ amplitude wave it is shown that high $\mathrm{CCN}$ suppresses the clearing of the cloud. It is also true that low CCN suppresses the clearing of the cloud in the case of the $150 \mathrm{~m}$ amplitude wave. Bottom: plot shows the corresponding domain-averaged LWP.

Feingold et al. (2010); hence, domain size is important to the findings. Nevertheless, the model shows that this clearance occurs over several hours, whereas for the case with the gravity wave the reduction in cloud coverage is coincident with the wave. This rapid clearing after the gravity wave is consistent with the satellite observations.

\section{Discussion}

The model results suggest that gravity waves are able to result in a rapid clearing of the cloud only when they occur after sunrise. In the simulations presented, this is likely related to the fact that the Sc starts to become decoupled after sunrise. Decoupling of the boundary layer was a common occurrence away from the coastal region during the VOCALS campaign (Jones et al., 2011), even in the mid-morning, before solar insolation leads to stronger decoupling; however, despite the decoupling there was still often $100 \%$ cloud cover.

In our simulations, when there is strong coupling between the sea and the cloud-topped boundary layer, gravity waves do not cause a rapid clearing of the cloud, as the fluxes of water vapour from the ocean surface are sufficient to promote condensation and fill in the cloud, thus restoring the longwave cooling that drives the turbulence within the boundary layer.

However, when gravity waves were specified to occur in Sc that were less strongly coupled, they did result in a rapid clearing of the cloud. The decoupled cloud was more patchy in appearance and therefore, after lifting, cloud-top entrainment was enhanced by horizontal gradients in evaporation, reducing the total water mixing ratio. After the ascent the majority of the cloud evaporated in the trough of the gravity wave due to adiabatic warming, which suppresses radiative cooling of the boundary layer air by virtue of increased shortwave heating and reduced longwave cooling, thus reducing the LWP further. Since the cloud is less strongly coupled to the surface, the flux of water vapour is insufficient to replenish the cloud.

For gravity waves that occurred in a strongly coupled Sc the clearing of the cloud occurred over a much longer timescale (if at all), and was much slower. In this case the lifting caused by the gravity wave resulted in an increase in warm rain formation, which after precipitating out of the cloud resulted in a Sc with lower LWP, but still with $100 \%$ cloud coverage. The slow clearing of the cloud that sometimes occurred in these cases was due to the warming of the boundary layer throughout the day, and the associated increase in saturation vapour mixing ratio.

Hence, in the morning, strong coupling between the surface and cloud layer renders the effect of the gravity wave minimal as the surface fluxes suppress drying of the cloud by entrainment and radiative heating. However, when the cloud decouples, the extra LWP during the upward cycle of the gravity wave leads to an enhanced entrainment, which mixes in more dry air. This effect is not compensated by surface fluxes as the cloud is decoupled, and therefore the result is that the cloud clears.

It is evident that $\mathrm{CCN}$ play a role in the clearing of the cloud. The model simulations presented were consistent with the observations that POCs tend to form in the transition region since, at least for the single-wave simulations, cloud 
(a) Time $=3: 00$ (start)

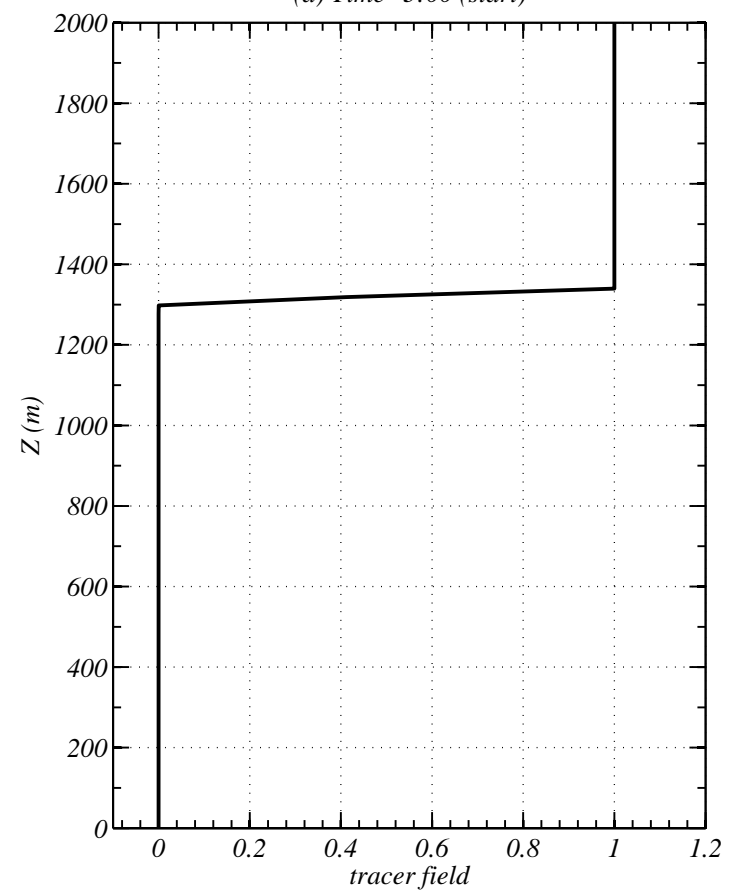

(b) Time $=12: 00$

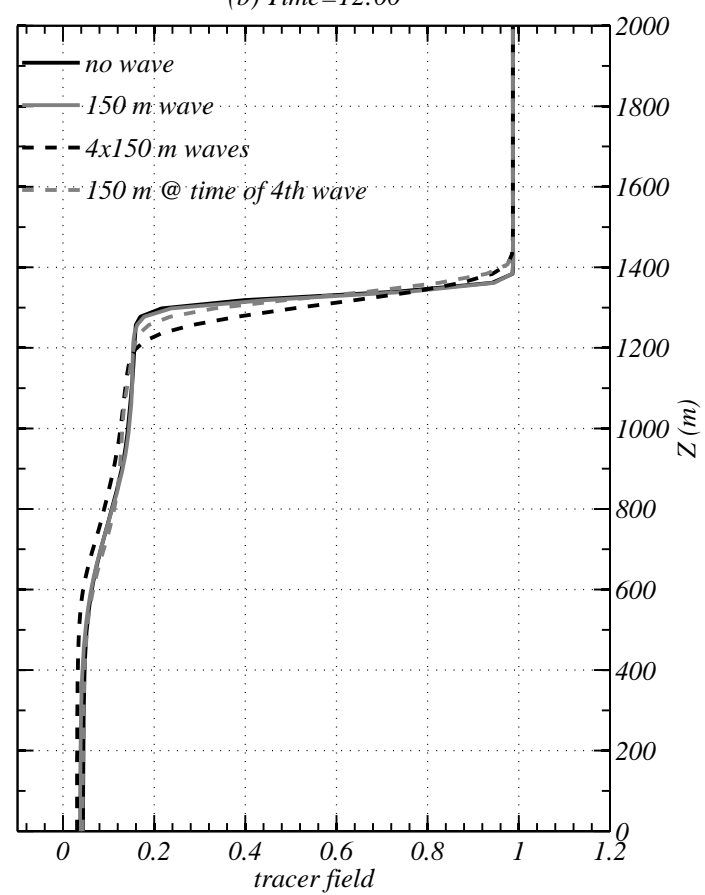

Fig. 19. (a) shows the initial concentration of a passive tracer that was set up to look at air entraining from above the inversion; (b) shows the concentration of the tracer $9 \mathrm{~h}$ into the simulation for cases without a wave, with a $150 \mathrm{~m}$ wave occurring early in the morning, for $4 \times 150 \mathrm{~m}$ amplitude waves and for a single $150 \mathrm{~m}$ wave occurring at the same time as the last wave in the $4 \times$ case.

clearing only occurred when $\mathrm{CCN}$ concentrations were specified to be medium. However, it is noted that, in reality, $\mathrm{CCN}$ variability may be significant across all three regions; therefore, using averages for each of these regions may not give a completely accurate picture. Nevertheless, it does give some useful insights into the processes that cause the cloud to clear. Wang et al. (2010) investigated aerosol perturbations on the generation of POCs using $\sim 100 \mathrm{~km}^{2}$-scale model simulations at $300 \mathrm{~m}$ horizontal resolution, finding that gradients in aerosol were indeed significant in promoting the development of POCs. This effect has not been investigated here.

The effect that CCN concentrations and warm-rain formation has on LWP in the simulations is notable. Here it is shown that initially the LWP is lower in the runs with lower CCN concentrations, as might be expected because, for a given LWP, lower drop concentrations lead to faster rain formation; however, later in the simulations the opposite was true. Such findings highlight the non-linearity of aerosol-cloud interactions.

Other reasons that the clearing is observed preferentially at distances away from the coast may be due to boundary layer depth, which increases with distance away from the coast, or SST, which decreases a short distance from the coast and then starts to increase with distance into the transition zone (see Bretherton et al., 2010). However, investigating these effects is outside of the scope of this study.
The question of whether clearing of the cloud will lead to the formation of POCs is difficult to answer with the current set of simulations as the domain size is not large enough to model mesoscale circulations and their self-organisation. Nevertheless, the simulation with four gravity waves displayed an increase in turbulence after the cloud cleared, due to drizzle evaporating and causing cold pools; this led to a cloud layer that was more strongly coupled to the surface moisture fluxes towards the end of the simulation. Cold pools have been shown to be important components of open MCC circulations in an aircraft case study during the same project (Wood et al., 2011a). Our results support the finding of Wood et al. (2011a), who suggest that warm rain is not a sufficient condition for the formation of POCs, since at least in our simulations the clearing of the cloud occurs by mixing in of dry air, with cold pools serving to reinvigorate $\mathrm{Cu}$-like convection.

\section{Conclusions}

The conclusions drawn from the study are as follows:

- Gravity waves are able to promote irreversible changes to the cloud microphysics inside Sc clouds, such that the resulting thermodynamics alter the dynamics of the MBL, and lead to a more patchy cloud regime, which may be associated with POCs. 

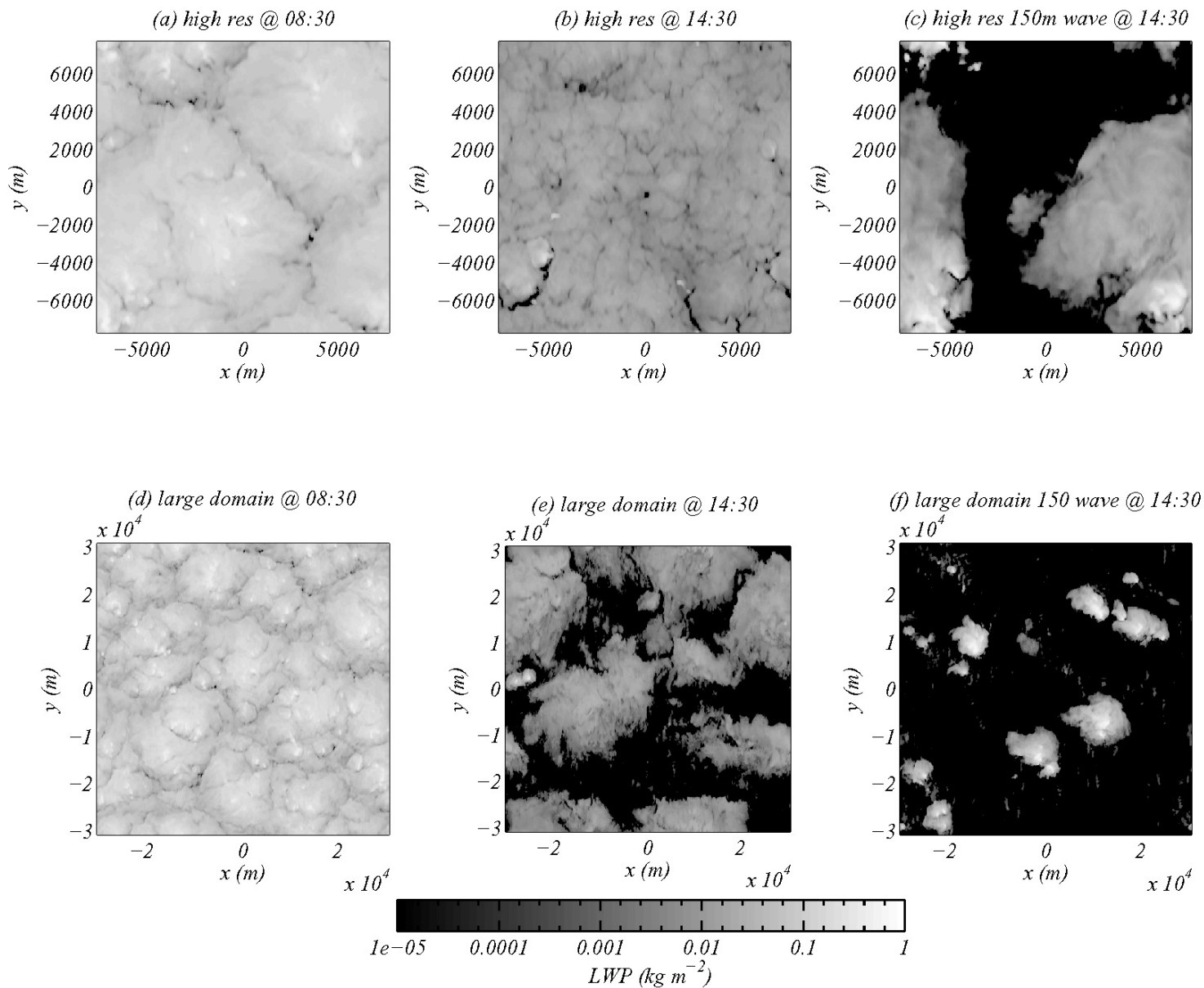

Fig. 20. Snapshots of liquid water path for high-resolution runs (a-c) and for large-domain runs with the same resolution as the control (d-f). (a), (b), (d) and (e) are runs without gravity waves, whereas (c) and (f) are liquid water paths for runs with a single gravity wave occurring at the time of the 4 th wave.

- Within the simulations presented, it was a combination of the entrainment of dry air from above the inversion and a reduction in longwave cooling that was responsible for the rapid clearing of the cloud after the gravity wave occurred.

- Warm rain was important to reinvigorating cumulus clouds following the clearing of the Sc. This was because the rain evaporated and resulted in colder air in the MBL, which displaced the warmer air and resulted in greater convective instability.

- Using transition or "medium" CCN values was important to simulate the slow clearing of the cloud that occurred towards the end of the simulation. Coastal or "high" CCN was able to suppress the clearing of the cloud because of cloud-top radiative cooling, which is consistent with observations of fewer POCs in the "coastal" region. Remote or "low" CCN also suppressed the clearing over the day because it resulted in a more coupled cloud.
- Using multiple waves to force the simulation resulted in a more dramatic clearing of the cloud, similar to that observed. Timing of the waves needs to be later in the day (after sunrise) for rapid clearing of the cloud.

- It appears that both hypotheses are true to an extent. The evidence presented from the model is that entrainment of dry air from aloft occurs where there is a rapid clearing of the cloud shortly after the gravity wave; however, warm rain may play a role in the transition to open cellular convection through the generation of cold pools that result in increased convective instability.

Questions for further research are the following: (i) "is there a threshold LWP above which a decoupled boundary layer cloud will not rapidly clear after a gravity wave?", (ii) "is the detailed effect of CCN important for the formation of POCs?" and (iii) "does this effect occur in regions that have smaller temperature and moisture inversions than the SEP?". 


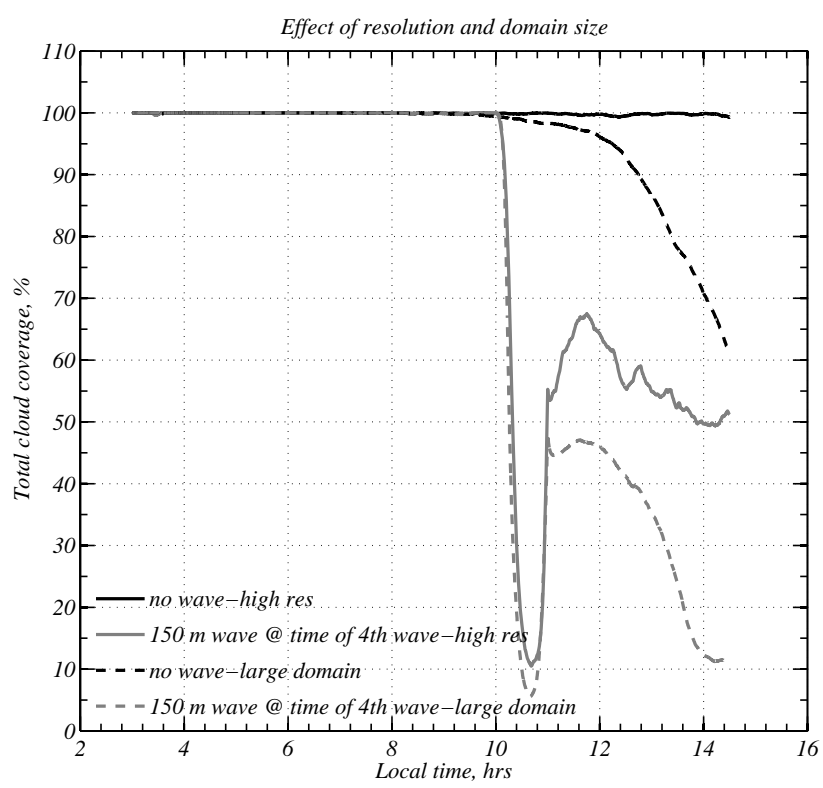

Fig. 21. Total cloud coverage for the high-resolution and the largedomain runs, both with and without gravity waves. Solid lines are for the high-resolution run and dashed lines are for the large-domain run. Black lines are runs without a gravity wave, and grey lines are runs with a single gravity wave at the time of the 4th wave.

Acknowledgements. We would especially like to acknowledge Paul Williams and his colleagues at the Manchester FGAM who provided the in situ aerosol measurements and for their particular care and attention to the quality control and assurance of these data products. We would like to acknowledge the pilots of the BAe-146 aircraft. Funding from NERC is acknowledged for the VOCALS project under the grant code NE/F019874/1. Acknowledgement is also given to Dr. Dave Topping (University of Manchester/National Centre for Atmospheric Science) who provided the thermodynamic data for the aerosol so that the $\mathrm{CCN}$ properties could be predicted.

Edited by: R. Wood

\section{References}

Agee, E. N.: Observations from space and thermal convection: a historical perspective, B. Am. Meteorol. Soc., 65, 938-949, 1984.

Albrecht, B. A.: Aerosols, cloud microphysics and fractional cloudiness, Science, 245, 1227-1230, 1989.

Allen, G., Coe, H., Clarke, A., Bretherton, C., Wood, R., Abel, S. J., Barrett, P., Brown, P., George, R., Freitag, S., McNaughton, C., Howell, S., Shank, L., Kapustin, V., Brekhovskikh, V., Kleinman, L., Lee, Y.-N., Springston, S., Toniazzo, T., Krejci, R., Fochesatto, J., Shaw, G., Krecl, P., Brooks, B., McMeeking, G., Bower, K. N., Williams, P. I., Crosier, J., Crawford, I., Connolly, P., Allan, J. D., Covert, D., Bandy, A. R., Russell, L. M., Trembath, J., Bart, M., McQuaid, J. B., Wang, J., and Chand, D.: South East Pacific atmospheric composition and variability sampled along $20^{\circ} \mathrm{S}$ during VOCALS-REx, Atmos. Chem. Phys., 11, 5237-5262, doi:10.5194/acp-11-5237-2011, 2011.
Allen, G., Vaughan, G., Toniazzo, T., Coe, H., Connolly, P. J., Yuter, S., Burleyson, C. D., Minnis, P., and Ayers, J. K.: Gravity-waveinduced pertubations in marine stratocumulus, Q. J. Roy. Meteorol. Soc., 139, 32-45, doi:10.1002/qj1952, 2012.

Berner, A. H., Bretherton, C. S., and Wood, R.: Large-eddy simulation of mesoscale dynamics and entrainment around a pocket of open cells observed in VOCALS-REx RF06, Atmos. Chem. Phys., 11, 10525-10540, doi:10.5194/acp-11-10525-2011, 2011.

Bretherton, C. S., Macvean, M. K., Bechtold, P., Chlond, A., Cotton, W. R., Cuxart, J., Cuijpers, H., Khairoutdinov, M., Kosovic, B., Lewellen, D. C., Moeng, C. H., Siebesma, A. P., Stevens, B., Stevens, D. E., Sykes, I., and Wyant, M. C.: An intercomparison of radiatively driven entrainment and turbulence in a smoke cloud, as simulated by different numerical models, Q. J. Roy. Meteorol. Soc., 125, 391-423, 1999.

Bretherton, C. S., Uttal, T., Fairall, C. W., Yuter, S., Weller, R., Baumgardner, D., Comstock, K., Wood, R., and Raga, G.: The EPIC 2001 stratocumulus study, B. Am. Meteorol. Soc., 85, $967-$ 977, 2004.

Bretherton, C. S., Wood, R., George, R. C., Leon, D., Allen, G., and Zheng, X.: Southeast Pacific stratocumulus clouds, precipitation and boundary layer structure sample along $20^{\circ} \mathrm{S}$ during VOCALS-REx, 10, 10639-10654, 2010.

Connolly, P. J., Möhler, O., Field, P. R., Saathoff, H., Burgess, R., Choularton, T., and Gallagher, M.: Studies of heterogeneous freezing by three different desert dust samples, Atmos. Chem. Phys., 9, 2805-2824, doi:10.5194/acp-9-2805-2009, 2009.

Connolly, P. J., Emersic, C., and Field, P. R.: A laboratory investigation into the aggregation efficiency of small ice crystals, Atmos. Chem. Phys., 12, 2055-2076, doi:10.5194/acp-12-20552012, 2012.

Dearden, C., Connolly, P. J., Choularton, T. W., and Field, P. R.: Evaluating the effects of microphysical complexity in idealised simulations of trade wind cumulus using the Factorial Method, Atmos. Chem. Phys., 11, 2729-2746, doi:10.5194/acp-11-27292011, 2011.

Edwards, J. M. and Slingo, A.: Studies with a flexible new radiation code. Part I. Choosing a configuration for a large scale model, Q. J. Roy. Meteorol. Soc., 122, 689-719, 1996.

Feingold, G., Koren, I., Wang, H., Xue, H., and Brewer, W. A.: Precipitation-generated oscillations in open cellular cloud fields, Nature, 466, 849-852, 2010.

Garay, M. J., Davies, R., Averill, C., and Westphal, J. A.: Actinoform clouds. Overlooked examples of cloud self-organization at the mesoscale, B. Am. Meteorol. Soc., 85, 1585-1594, 2004.

Garreaud, R. D. and Muñoz, R. C.: The Diurnal Cycle in Circulation and Cloudiness over the Subtropical Southeast Pacific: A Modeling Study, J. Climate, 17, 1699-1710, 2004.

Gray, M. E. B., Petch, J. C., Derbyshire, S. H., Brown, A. R., Lock, A. P., Swann, H. A., and Brown, P. R. A.: Version 2.3 of the Met Office Large Eddy Model: Part II. Scientific Documentation, Tech. rep., 2001.

Hubert, L. F.: Mesoscale cellular convection, Tech. rep., 1966.

Jiang, Q. and Wang, S.: Impact of Gravity Waves on Marine Stratocumulus Variability, J. Atmos. Sci., 69, 3634-3652, 2012.

Jones, C. R., Bretherton, C. S., and Leon, D.: Coupled vs. decoupled boundary layers in VOCALS-REx, Atmos. Chem. Phys., 11, 7143-7153, doi:10.5194/acp-11-7143-2011, 2011. 
Knippertz, P., Chagnon, J. M., Foster, A., Lathouwers, L., Marsham, J. H., Methven, J., and Parker, D. J.: Research flight observations of a prefrontal gravity wave near the southwestern UK, Weather, 65, 293-297, 2010.

Martin, G. M., Johnson, D. W., and Spice, A.: The measurement and parameterisation of effective radius of droplets in warm stratocumulus clouds, J. Atmos. Sci., 51, 1823-1842, 1994.

Morrison, H., Curry, J. A., and Khvorostyanov, V. I.: A new doublemoment microphysics parameterisation for application in cloud and climate models, J. Atmos. Sci., 62, 1665-1677, 2005.

Rahn, D. A. and Garreaud, R.: Marine boundary layer over the subtropical southeast Pacific during VOCALS-REx - Part 1: Mean structure and diurnal cycle, Atmos. Chem. Phys., 10, 4491-4506, doi:10.5194/acp-10-4491-2010, 2010.

Rogers, R. R. and Yau, M. K.: A short course in cloud physics, vol. 113 of "International series in natural philosophy", "Pergamon press", 3 edn., 1989.

Seifert, A. and Beheng, K. D.: A two moment cloud microphysics parameterisation for mixed phase clouds. Part II: Maritime vs. continental deep convective storms, Meteor. Atmos. Phys., 92, 67-82, 2006.

Stevens, B., Vali, G., Comstock, K., Wood, R., Zanten, M. C. v., Austin, P. H., Bretherton, C. S., and Lenschow, D. H.: Pockets of open cells (POCs) and drizzle in marine stratocumulus, B. Am. Meteorol. Soc., 86, 51-57, 2005.

Twomey, S.: The nuclei of natural cloud formation: the supersaturation in natural clouds and the variation of cloud droplet concentration, Geofis pura et appl., 43, 243-249, 1959.
Twomey, S.: The influence of pollution on the shortwave albedo of clouds, J. Atmos. Sci., 34, 1149-1152, 1977.

Wang, H., Feingold, G., Wood, R., and Kazil, J.: Modelling microphysical and meteorological controls on precipitation and cloud cellular structures in Southeast Pacific stratocumulus, Atmos. Chem. Phys., 10, 6347-6362, doi:10.5194/acp-10-6347-2010, 2010.

Wood, R. and Hartmann, D. L.: Spatial variability of liquid water path in marine low cloud: the importance of mesoscale cellular convection, J. Climate, 19, 1748-1764, 2006.

Wood, R., Bretherton, C. S., Leon, D., Clarke, A. D., Zuidema, P., Allen, G., and Coe, H.: An aircraft case study of the spatial transition from closed to open mesoscale cellular convection over the Southeast Pacific, Atmos. Chem. Phys., 11, 2341-2370, doi:10.5194/acp-11-2341-2011, 2011a.

Wood, R., Mechoso, C. R., Bretherton, C. S., Weller, R. A., Huebert, B., Straneo, F., Albrecht, B. A., Coe, H., Allen, G., Vaughan, G., Daum, P., Fairall, C., Chand, D., Gallardo Klenner, L., Garreaud, R., Grados, C., Covert, D. S., Bates, T. S., Krejci, R., Russell, L. M., de Szoeke, S., Brewer, A., Yuter, S. E., Springston, S. R., Chaigneau, A., Toniazzo, T., Minnis, P., Palikonda, R., Abel, S. J., Brown, W. O. J., Williams, S., Fochesatto, J., Brioude, J., and Bower, K. N.: The VAMOS Ocean-Cloud-AtmosphereLand Study Regional Experiment (VOCALS-REx): goals, platforms, and field operations, Atmos. Chem. Phys., 11, 627-654, doi:10.5194/acp-11-627-2011, 2011 b. 